OPEN ACCESS

Edited by: Brian Godman, University of Strathclyde, United Kingdom

Reviewed by: Luis Laranjeira,

Eli Lilly, Portugal

Godfrey Mutashambara Rwegerera, University of Botswana, Botswana

*Correspondence: Santi Di Pietro santi.dipietro01@universitadipavia.it

Specialty section: This article was submitted to Pharmaceutical Medicine and Outcomes Research,

a section of the journal

Frontiers in Pharmacology

Received: 15 June 2020 Accepted: 27 October 2020 Published: 09 December 2020

Citation:

Lo Bianco G, Di Pietro S, Mazzuca E, Imburgia A, Tarantino L, Accurso G, Benenati V, Vernuccio F, Bucolo C,

Salomone $S$ and Riolo M (2020)

Multidisciplinary Approach to the

Diagnosis and In-Hospital Management of COVID-19 Infection: A

Narrative Review.

Front. Pharmacol. 11:572168. doi: 10.3389/fphar.2020.572168

\section{Multidisciplinary Approach to the Diagnosis and In-Hospital Management of COVID-19 Infection: A Narrative Review}

\author{
Giuliano Lo Bianco ${ }^{1,2}$, Santi Di Pietro ${ }^{3,4 *}$, Emilia Mazzuca ${ }^{5}$, Aurelio Imburgia ${ }^{6}$, \\ Luca Tarantino ${ }^{7}$, Giuseppe Accurso ${ }^{8}$, Vincenzo Benenati ${ }^{9}$, Federica Vernuccio ${ }^{10}$, \\ Claudio Bucolo ${ }^{1}$, Salvatore Salomone ${ }^{1}$ and Marianna Riolo ${ }^{11}$
}

\begin{abstract}
${ }^{1}$ Department of Biomedical and Biotechnological Sciences, School of Medicine, University of Catania, Catania, Italy, ${ }^{2}$ Anesthesiology and Pain Department, Fondazione Istituto G. Giglio, Cefalù, Italy, ${ }^{3}$ Emergency Medicine Fellowship Programme, University of Pavia, Pavia, Italy, ${ }^{4}$ Emergency Department, St Mary's Hospital, Imperial College Healthcare NHS Trust, London, United Kingdom, ${ }^{5}$ Unità operativa Complessa di Pneumologia, A.O. Ospedali Riuniti Villa Sofia Cervello, Palermo, Italy, ${ }^{6}$ San Marino State Hospital, Cailungo, San Marino Republic, ${ }^{7}$ Cliniche Humanitas Gavazzeni, U.O. Elettrofisiologia, Bergamo, Italy, ${ }^{8}$ Department of Surgical, Oncological and Oral Science (Di.Chir.On.S.), Section of Anaesthesia, Analgesia, Intensive Care and Emergency, Policlinico Paolo Giaccone, University of Palermo, Palermo, Italy, ${ }^{9}$ Polyclinique du Maine, Laval, Pays de la Loire, France, ${ }^{10}$ Section of Radiology, Department of Biomedicine, Neurosciences and Advanced Diagnostics (BIND), University of Palermo, Palermo, Italy, ${ }^{11}$ Struttura Complessa di Neurologia, Ospedale Santa Croce di Moncalieri, Asl TO5, Moncalieri (TO), Italy
\end{abstract}

Severe Acute Respiratory Syndrome Coronavirus 2 (SARS-CoV-2 or COVID-19 disease) was declared a pandemic on 11th March 2020 by the World Health Organization. This unprecedented circumstance has challenged hospitals' response capacity, requiring significant structural and organizational changes to cope with the surge in healthcare demand and to minimize in-hospital risk of transmission. As our knowledge advances, we now understand that COVID-19 is a multi-systemic disease rather than a mere respiratory tract infection, therefore requiring holistic care and expertise from various medical specialties. In fact, the clinical spectrum of presentation ranges from respiratory complaints to gastrointestinal, cardiac or neurological symptoms. In addition, COVID19 pandemic has created a global burden of mental illness that affects the general population as well as healthcare practitioners. The aim of this manuscript is to provide a comprehensive and multidisciplinary insight into the complexity of this disease, reviewing current scientific evidence on COVID-19 management and treatment across several medical specialties involved in the in-hospital care of these patients.

Keywords: COVID-19, hospital care, multispecialist care, pandemic (COVID-19), hospital response capability

\section{INTRODUCTION}

Since COVID-19 has been declared a Public Health Emergency of International concern on the 30th January 2020, more than 39 millions of people worldwide have been infected (https://covid19.who.int/).

Hospitalized patients with COVID-19 require a multidisciplinary approach as the infection can lead to a plethora of clinical scenarios. Most commonly, patients are hospitalized for respiratory insufficiency, which requires oxygen administration delivered in several forms including mechanical ventilation in the most severe cases (Marini and Gattinoni, 2020). Indeed, a subgroup of infected individuals-i.e., approximately $5 \%$ of COVID-19 patients - rapidly progress to acute respiratory 
distress syndrome (ARDS), often associated with multiple organ failure (MOF), sepsis and septic shock requiring admission to intensive care units (ICUs) (Marini and Gattinoni, 2020).

Central nervous system involvement in COVID-19 infection has been noticed since the early stages of the pandemic. In fact, symptoms such as anosmia or ageusia are relatively common among infected individuals (Guan et al., 2020). In addition, other neurological manifestations have been reported, such as meningoencephalitis and stroke, the latter being related to the prothrombotic state observed with this infection (Zhang et al., 2020a). Gastrointestinal symptoms (GIS), as nausea, vomiting, abdominal pain and diarrhea, may be an early manifestation of COVID-19 disease, and some studies suggest that the presence of GIS may indicate a higher probability of a severe course (Jin et al., 2020b; Guan et al., 2020).

Cardiovascular manifestations of COVID-19 such as myocarditis, arrhythmias, acute coronary syndromes and venous thromboembolism also dictate hospital admission and ad-hoc treatment (Clerkin et al., 2020). Eventually, a global burden of mental illness has been associated with the current pandemic. Indeed, these unprecedented circumstances have induced adverse psychological outcomes in the general population as well as among healthcare workers, which range from anxiety, depression or fear up to violence and suicidal ideation (Kisely et al., 2020; Rossi et al., 2020).

This paper reviews the available literature, guidelines and guidance models from multiple medical societies until 3rd October 2020. It aims to provide multidisciplinary guidance for hospital clinicians who are currently involved in the management of COVID-19 patients.

\section{Management of COVID-19 Patients in the Emergency Department Structural, Organizational and Logistical Response to the Pandemic}

Emergency Departments (EDs) are playing on a global scale a pivotal role in providing an adequate response to healthcare demand during COVID-19 pandemic. Traditionally, EDs have to both guarantee emergency care to patients hospitalized via pre-hospital emergency services, and triage and treat a vast number of self-presenting patients on a 24/7 basis. In current pandemic times many EDs are experiencing an unprecedented surge of caseload, that can easily overwhelm ED's response capacity, already chronically affected by understaffing, overcrowding, limited resources and poor infrastructures. Moreover, ED's overcrowding during a pandemic can dramatically increase the risk of facilitating and catalyzing the spread of infection among patients and operators. Therefore, now more than ever efforts should be made at all levels to minimize inappropriate ED utilization (Karan, 2020) and to adequately triage patients suspected of SARS-CoV-2 identifying those requiring hospitalization.

The increased demand in health care and the need to guarantee workers and patients safety during epidemic has led to the need of structural, organizational and logistical changes of EDs. Resilience capacity and preparedness of EDs to adapt to the pandemic might be facilitated by the pre-existence of institutional mass casualties' incidents (MCI) protocols. However, several differences exist between MCI and a viral pandemic. Indeed, MCI typically have a finite number of cases concentrated in an initial peak followed by a progressive decline of visits and hospital admissions over time. In addition to that, managing patients during MCI usually does not require the rigid need of standard precautions as during COVID-19 pandemic. Nevertheless, when facing a viral outbreak, prediction models can help hospitals to adapt their response and the deployment of resources (Gagliano et al., 2020; Paganini et al., 2020).

Interestingly, during the ongoing pandemic similar solutions have been adopted by authors working in very different contexts across the globe. Tents or tent-like structures have been widely used in several countries. Typically positioned outside EDs, these structures offer a simple solution to expand ED's spaces and can serve as waiting areas as well as for the initial triage of patients (Chen et al., 2020a; Liang et al., 2020; Paganini et al., 2020).

In currently available literature, there is wide agreement on the necessity of creating two distinct and physically separated pathways for suspected COVID-19 patients (also defined as "dirty" or "red" or "infectious" pathway) from non-COVID-19 patients (often referred as "green" or "clean" pathway) (Chen et al., 2020a; Asperges et al., 2020; Gagliano et al., 2020; Liang et al., 2020; Paganini et al., 2020; Paglia et al., 2020). This can be achieved by readapting other hospital buildings in the hospital or alternatively by expanding ED's space into adjacent repurposed areas. Another possibility is represented by the creation of a filter zone inside ED's pre-existing spaces by using available construction plastic, similar to the barriers in the refrigeration compartment of stores that are suspended to guarantee a droplet barrier (Paganini et al., 2020).

Whatever areas are repurposed to serve as temporary COVID19 EDs, it is essential to share decisions with all hospital stakeholders and particularly with hospital engineers: in fact, technical interventions may be needed to ensure availability of oxygen and compressed air, and correct functioning of vacuum and electrical circuits (Paganini et al., 2020). Each area of the ED, i.e., the red and green areas, should use dedicated equipment (e.g., ECG, ultrasound and $\mathrm{x}$-ray machines etc.), to avoid risk of contact-related contagion. Moreover, using portable imaging devices will reduce the need to transfer patients through the hospital, thus helping to reduce droplet spreading (Asperges et al., 2020; Gagliano et al., 2020).

Eventually, during the course of the current COVID-19 epidemic some institutions have implemented strategies of technology-based clinical evaluation (Turer et al., 2020; Wittbold et al., 2020). The adoption of such methods of digital care delivery in Emergency departments is showing promising results, as they can help minimizing direct contact between operators and infectious patients, hence increasing operator's safety, at the same time also reducing the utilization of personal protective equipment.

\section{Triage}

One of the greatest difficulties encountered by ED's healthcare professionals during the current pandemic is certainly represented by triage. Indeed, COVID-19 patients can present with respiratory syndromes indistinguishable from other 
common conditions. Moreover, respiratory symptoms may even be absent, with patients complaining only of fever and/or a number of other systemic symptoms (Lu et al., 2020a). The variegated clinical picture poses a challenge for early detection during triage at the emergency department (ED). Initially, the World Health Organization (WHO) triage recommendation focused on patients with pneumonia and a recent travel history to Wuhan, based on the knowledge of the outbreak at that time (Global Surveillance, 2020). These criteria were broadened from the 27th of February 2020, to include all patients with acute respiratory disease with no alternative etiology and a history of residence in any country reporting current outbreaks (Liang et al., 2020). Interestingly, a recent study from Singapore demonstrated that using broader ED's triage criteria as compared to official recommendations, can increase the sensitivity of detection of COVID-19 cases (Liang et al., 2020). Similarly, many healthcare trusts, hospitals and scientific medical societies worldwide have proposed a various number of different triage criteria (Paglia et al., 2020; RCEM Quality Policy, 2020). A higher sensitivity of screening of COVID-19 patient's at triage will automatically translate into increased inpatient resource utilization, in particular a higher requirement of hospital beds. However, such effort allows to guarantee adequate separation of patients into the most appropriate pathway and reduces the risk of nosocomial transmission of the virus (Liang et al., 2020). In any case, there will always be a risk of nosocomial transmission from asymptomatic COVID-19 patients admitted for other reasons. Hence, each patient accessing the hospital should be considered infectious until proven otherwise and should therefore be provided with a surgical mask (Paglia et al., 2020).

\section{Laboratory Test}

A baseline number of laboratory investigations, including full blood count, serum electrolytes, renal and hepatic function and coagulation study should be performed in all suspected COVID-19 cases (Paglia et al., 2020; RCEM Quality Policy, 2020). Patients usually show normal leukocytes count and lymphopenia even though leukopenia and leukocytosis have been reported (Rodriguez-Morales et al., 2020). C-reactive protein, hsTroponin, D-Dimer, serum ferritin and lactate dehydrogenase have shown to have prognostic value in initial studies (Tan et al., 2020; Zhou et al., 2020). Blood cultures and testing for atypical bacteria should also be considered (Turer et al., 2020; Rodriguez-Morales et al., 2020).

Procalcitonin is known to be a useful marker to guide initiation and duration of antibiotic treatment in respiratory infections, and preliminary experience in COVID-19 patients seems to confirm current knowledge (Zhou et al., 2020; Schuetz et al., 2017). In particular, dosage of procalcitonin can help in guiding antibiotic appropriateness and in reducing duration of treatments and antibiotic-related side effects (Schuetz et al., 2017). Pulse oximetry should be performed both at rest and after exercise (i.e., 6-min walking test), because a measurement of oxygen saturation at rest only may not detect an underlying respiratory insufficiency (Paglia et al., 2020; RCEM Quality Policy, 2020; FADOI, 2020). A more accurate and reliable assessment of the respiratory status and oxygen requirement can be easily obtained with an arterial blood gas analysis, which is recommended as a baseline test by several scientific societies and institutions (Paglia et al., 2020; RCEM Quality Policy, 2020; FADOI, 2020). Similarly, nasopharyngeal swabs should be routinely performed in all patients investigated for possible COVID-19 disease, as suggested by WHO guidelines (Paglia et al., 2020; RCEM Quality Policy, 2020; FADOI, 2020). SARS-CoV-2 can be detected 1-2 days before the onset of symptoms in upper respiratory tract samples and usually persist for 7-14 days, although cases of prolonged swab positivity have been reported (World Health Organization, 2020c).

Standard precautions assume that every person is potentially infected or colonized with a pathogen that could be transmitted in the healthcare setting.

The swab is also an effective tool for contact-tracing and it is useful to implement prevention and control measures.

In relation to each nation'|'s testing ability, European Center for disease Prevention and Control recommends nasopharyngeal swab in the following categories (presented in order of importance) (European Center for Disease Prevention and Control (ECDC), 2020a; European Center for Disease Prevention and Control (ECDC), 2020b; European Center for Disease Prevention and Control (ECDC), 2020c):

- Patients hospitalized with severe acute respiratory infection for a better clinical management and to provide the rapid patient isolation and implementation of individual protection measures.

- All cases of acute respiratory infection in hospitalized patients or long-term care facilities in order to draw up a prevention program for dedicated staff and for the early treatment of fragile patients.

- All patients admitted to sentinel hospitals with severe acute respiratory infection in order to assess virus circulation in the population.

- Elderly patients and patients with multiple comorbidities to prevent any worsening of the respiratory picture.

\section{Imaging}

Baseline chest radiographs have a sensitivity for the diagnosis of COVID-19 of 69\% (Ambrose et al., 2019). As such, chest radiographs are of little diagnostic value in early stages and its routine use as a screening tool in the early course of the disease is not recommended, except in very exceptional resource-constrained environments (Salehi et al., 2019; Rubin et al., 2020). The main role of chest radiographs is played for assessing disease progression in hospitalized patients, bacterial superinfection, pneumothorax and pleural effusion (Salehi et al., 2019).

Chest CT has a very high sensitivity (97\%) for the diagnosis of COVID-19 disease, but a low specificity (i.e., 25-56\%), due to overlapping of imaging features of other viral or atypical pneumonia or with non-infectious diseases, such as vasculitis, dermatomyositis (Jin et al., 2020a; Caruso et al., 2020; Kooraki et al., 2020; Tao et al., 2020).

The main findings of COVID-19 patients on both chest radiographs and CT include bilateral pneumonia in the majority of hospitalized patients, with the most common 
pattern being ground-glass opacities (GGO) with peripheral distribution and predominant involvement of the lower lung zones (Ambrose et al., 2019; Rodriguez-Morales et al., 2020). CT findings of COVID-19 pneumonia vary with time (Bernheim et al., 2020), from single or multiple focal GGO in the early stage, followed by multiple scattered patchy or agglomerated groundglass opacities that may progress to multiple patchy consolidations (Jin et al., 2020a). In addition, CT angiography can play a role in identifying pulmonary embolism, whose occurrence seems to be higher in COVID-19 patients and it should be suspected especially with evidence of high D-dimer levels (Helms et al., 2020). However, it may be logistically difficult to follow up hospitalized patients with multiple CT scans.

Although there is limited experience at this time on lung ultrasound (LUS) in COVID-19 patients, abundant literature supports the utility of lung ultrasound for a variety of respiratory conditions, including ARDS (Chiumello et al., 2018; Mojoli et al., 2019). This imaging technique offers some advantages over CT: it can be used in the ED or in the prehospital setting for a rapid triage of suspected cases (rule-in/rule-out) and therefore aid decision making for "red" or "green" pathway; it can help to quantify the severity of the disease, thus allowing for prognostic stratification; it can be repeated on patients admitted to hospital to monitor the progression of the disease and efficacy of therapeutic measures (Soldati et al., 2020a); it can be used to diagnose or rule out pneumothorax at the bedside, which is a potential complication of non-invasive and invasive ventilation (Carron, 2020). The main LUS findings in COVID-19 patients are thickening and irregularities of the pleural line, $B$ lines in a variety of patterns including (focal, multifocal, and confluent), consolidations and pleural effusions (the latter two mainly observed in case of superimposed bacterial pneumonia) (Peng et al., 2020).

Nevertheless, lung ultrasound should be performed by experienced physicians whose competencies have been objectively evaluated, and technique and reporting should be standardized as much as possible to facilitate reproducibility between physicians (Soldati et al., 2020b; Di Pietro et al., 2020).

All the above investigations, together with a thorough physical examination and history, will help the emergency physician to stratify the severity of COVID-19 patients and will aid decision making on admission and discharge. Based on current evidence and recommendations, patients should be discharged only when showing no signs of respiratory insufficiency and no requirement of oxygen, i.e., when normal arterial blood gas and saturation both at rest and after physical effort can be demonstrated. Beside the latter investigations, physicians should attentively observe and report the mechanics and work of breathing (Paglia et al., 2020; RCEM Quality Policy, 2020; FADOI, 2020).

\section{Treatment and Palliative Care}

Available treatments for the management of COVID-19 cases, including modalities of oxygen administration and ventilation as well as pharmacological interventions, will be discussed further below in this review.

In addition to therapeutic interventions, EDs and other wards involved in the care of COVID-19 cases should set up highquality palliative care pathways to ensure adequate and compassionate end of life care. This should ideally be accomplished through a multidisciplinary cooperation involving experts from relevant specialties (Fausto et al., 2020; Hendin et al., 2020).

\section{In-Hospital Infection Control}

As a suspected or confirmed COVID-19 patient enters the hospital, prevention of infection spread must be assured. In this regard, the use of Personal Protective Equipment (PPE) is essential for healthcare personnel (HCP), together with general hygiene rules (such as emphasized hand hygiene) (Interim Infection Prevention, 2020).

Ideally, suspected cases should be isolated as soon as possible in separated and well-ventilated areas, preferably a private room with door closed and a private bathroom. Airborne Infection Isolation Rooms (AIIRs) should be used for aerosol generating procedures, however their availability is limited in many hospitals (Saravia et al., 2007). Other interventions, such as cancellation of elective surgical procedures and the implementation of telemedicine-based strategies can help to diminish the number of people accessing the hospital (https://www.cms.gov/files/ document/cms-non-emergent-elective-medical-

recommendations.pdf; https://www.ama-assn.org/system/files/ 2020-05/state-elective-procedure-chart.pdf).

\section{A Multiorgan Disease: Pulmonary Involvement of COVID-19 Infection}

COVID-19 is characterized in the majority of cases by a mild respiratory disease, while in approximately $15 \%$ of cases a severe pneumonia is observed. The latter can progress to bilateral multifocal pneumonia, leading in $5 \%$ of total cases to ARDS, sepsis and septic shock (Wu and McGoogan, 2020).

During the incubation and in non-severe stages, a specific adaptive immune response is activated to eliminate the virus, but the development of this response can be possible if the host is healthy and with an appropriate genetic background (e.g., HLA). Conversely, when immune response is impaired, the virus will propagate and massive destruction of the affected tissues will occur, especially in organs that have high ACE2 expression (Shi et al., 2020). The damaged cells induce innate inflammation in the lungs that is largely mediated by pro-inflammatory macrophages and granulocytes. Lung inflammation is the main cause of lifethreatening respiratory disorders at a severe stage (Xu et al., 2020b).

As such, we can distinguish different stages of disease progression with different clinical syndromes:

Early infection phase the initial inflammatory response may cause in about $85 \%$ of cases mild illness with local or non-specific systemic symptoms such as fever (88-99\% of cases), fatigue (38-70\%), dry cough (59-68\%), anorexia (40\%), myalgias (15-35\%), dyspnea (19-31\%), sputum production $(27-34 \%)$. Gastrointestinal symptoms (nausea, diarrhea), rhinorrhea, sore throat and pharyngalgia have also been reported (Lechien et al., 2020; Tinku, 2020). These patients usually show no hypoxia on blood gas analysis (BGA), present with a respiratory rate (RR) less than 22 breaths/minute $(\mathrm{b} / \mathrm{m})$ and a negative chest radiograph. Most of them do not progress beyond this phase and their 
management should be assigned to general practitioners (GP) (Lechien et al., 2020; Lopes et al., 2020; Tinku, 2020).

Pulmonary phase SARS-CoV-2 shows on its surface a glycoprotein that binds angiotensin-converting enzyme 2 (ACE2), a receptor located on type 2 pneumocytes. Through this way the virus infiltrates the lung parenchyma and begins to proliferate (Li and $\mathrm{Ma}, 2020$ ). Increased levels of ACE2 were found in SARS-CoV-2 infected cells, suggesting that ACE2 is also involved in post-infection regulation, including immune response, cytokine secretion, and viral genome replication ( $\mathrm{Li}$ and $\mathrm{Ma}, 2020$ ). About $15 \%$ of infected individuals develop a severe pneumonia with ARF requiring hospitalization and oxygen support. This group of patients need to be closely monitored as some of them may further exacerbate and develop a severe hyperinflammatory response (Tinku, 2020).

Hyperinflammatory phase in patients with severe clinical manifestation of COVID-19 a cytokine storm syndrome (CSS) may occur. The hallmark of CSS is an uncontrolled activation and amplification of the host immune system induced by SARS-Cov-2 infection, causing a systemic massive release of proinflammatory cytokines such as TNF-a, IL-1, IL-6 due to the lysis of cells (Heimfarth et al., 2020).

COVID-19 patients with severe symptoms exhibit an extreme decline in total $\mathrm{CD}^{+}$and $\mathrm{CD}^{+} \mathrm{T}$ cells in their circulation: IL-6 may induce apoptosis of $\mathrm{T}$ cells through the Fas/FaL pathway, while TNF-a and IFN-I may promote the attachment and retention of $\mathrm{T}$ cells in lymphoid organs (Fouladseresht et al., 2020).

CSS could also cause an increase in vascular permeability, resulting in severe damage of the alveolar cells and consequently development of acute respiratory failure (Leiva-Juárez et al., 2018; Zhang et al., 2020b).

Acute respiratory distress syndrome (ARDS) can be observed in these patients, which is characterized by several features, among which a $\mathrm{P} / \mathrm{F}$ ratio $<200$ on $\mathrm{BGA}$, increasing of $\mathrm{RR}$ above $30 \mathrm{~b} / \mathrm{m}$ and bilateral opacities at imaging (Vernuccio et al., 2020). An in depth discussion of ARDS will be presented later in this review.

Bronchoscopic procedures SarS-CoV-2 can be detected on $93 \%$ of bronchoalveolar lavage samples, thus showing a high sensitivity (Wang et al., 2020b). However, its routinary use has been discouraged due to the high risk of contagion to healthcare professionals (Wang et al., 2020b). Nevertheless, bronchoscopy should be considered in specific circumstances such as massive hemoptysis, acute foreign body aspiration, severe central airway obstruction, neutropenic fever with infiltrates and no clinical diagnosis or improvement (Pritchett et al., 2020).

Oxygen and Ventilatory therapy According to the ITS- AIPOSIC document (Harari et al., 2004) patients should be divided into four groups according to their respiratory status:

(1) green: $\mathrm{SaO} 2>94 \%, \mathrm{RR}<20 \mathrm{~b} / \mathrm{m}$ : if no $\mathrm{ARF}$ on $\mathrm{BGA}$, no oxygen needed;

(2) yellow: $\mathrm{SaO} 2<94 \%, \mathrm{RR}>20 \mathrm{~b} / \mathrm{m}$ : oxygen supply (up to 10-15 L/min) improves saturation;

(3) orange: $\mathrm{SaO} 2<94 \%, \mathrm{RR}>20 \mathrm{~b} / \mathrm{m}$ : poor response to oxygen $10-15 \mathrm{~L} / \mathrm{min}$ and needing high flow nasal oxygen (HFNO), continuous positive airway pressure (CPAP), NIV with very high FiO2;

(4) red: $\mathrm{SaO} 2<94 \%, \mathrm{RR}>20 \mathrm{~b} / \mathrm{m}$ : no response to all previous treatments or presenting respiratory distress with $\mathrm{PaO} 2 / \mathrm{FiO} 2$ $<200$ and needing endotracheal intubation (EI).

$\mathrm{O} 2$ saturation and RR should be re-evaluated no more than $2 \mathrm{~h}$ after therapy initiation and subsequently every $6 \mathrm{~h}$ (if target saturation and $\mathrm{RR}$ values are met and the patient remains stable) (Harari et al., 2004). High flow nasal cannula (HFNO) may be used as a bridge between oxygen and CPAP (continuous positive airway pressure) trial although this technique generates a relatively high amount of droplets (Harari et al., 2004). Ideally, CPAP should be delivered via a full-face non-vented mask, together with an expiratory viral filter and exhalation port; alternatively, an helmet can be used (as second choice) (Harari et al., 2004). Recommended values for positive end expiratory pressure (PEEP) are between 10 and $15 \mathrm{cmH} 2 \mathrm{O}$ (Harari et al., 2004; NHS Specialty Guides, 2020).

NIV should be used with a full-face non-vented mask and double circuit. Suggested initial settings are PS $8-10 \mathrm{cmH} 20+$ $60-100 \%$ FiO2. NIV should be considered for hypercapnic respiratory failure or to prevent hypercapnia in COPD patients (NHS Specialty Guides, 2020). Ideally, this should be delivered with a full face non-vented mask and a double circuit, using values of pressure support between 8 and $10 \mathrm{cmH} 20$ (Harari et al., 2004; NHS Specialty Guides, 2020).

In order to improve patient's comfort and compliance, administration of low doses of opioids can be considered. Humidification is generally discouraged, as it increases the quantity of droplet generation (NHS Specialty Guides, 2020).

Early intubation is mandatory if the patient does not respond adequately to CPAP or NIV (hypoxemia with $\mathrm{P} / \mathrm{F}<150-175$ after $1 \mathrm{~h}$ of CPAP/NIV in absence of BGA improvement, RR $>30 \mathrm{~b} / \mathrm{m}$; SAPS score $>34$, intolerance to ventilation, clinical decline) (NHS Specialty Guides, 2020; Antonelli et al., 2001).

Preliminary experience with self-proning of awake nonintubated patients has shown promising results in terms of improving oxygenation levels, although these findings and the safety of the procedure need to be confirmed in further trials (Caputo et al., 2020).

\section{Pharmacological Treatment}

Numerous studies have been conducted to find potential curative agents against COVID-19 disease, and many trials are still ongoing. Researcher's attention has been mostly directed towards drugs with direct antiviral activity and to those with immune-modulating or immune-suppressive effects.

Among the antiviral agents, Remdesivir (200 mg loading dose on day 1 , followed by $100 \mathrm{mg}$ daily for up to nine additional days) has been demonstrated to be superior to placebo in shortening the time to recovery in adults hospitalized with COVID-19 and evidence of lower respiratory tract infection (Beigel et al., 2020).

A large United Kingdom multicentric study has investigated the role of dexamethasone in hospitalized COVID-19 patients. Investigators have demonstrated a reduction in the 28 days mortality in the intervention group that received $6 \mathrm{mg}$ of 
dexamethasone (oral or intravenous) for up to 10 days (Horby and Lim, 2020). Interestingly, a subgroup analysis showed that the effects are more pronounced in patients mechanically ventilated or with high oxygen requirements as compared to those with no oxygen requirement (Horby and Lim, 2020). These findings suggest that dexamethasone plays an important role in the modulation of the excessive immune response observed in some cases of COVID-19 (see above Hyperinflammatory phase).

The efficacy of several other drugs have been investigated, such as tocilizumab, azithromycin, hydroxychloroquine, however results have been inconclusive (Oldenburg and Doan, 2020; Sanders, 2020; Skipper et al., 2020).

Numerous randomized controlled trials are currently being conducted to assess the efficacy of convalescent plasma (Li et al., 2020a). Current evidence suggests the safety of this therapeutic strategy and has shown promising results, therefore its use has been approved by the FDA and in several european countries ( $\mathrm{Li}$ et al., 2020b; Shen, 2020).

\section{A Multiorgan Disease: Gastroenterologic Involvement in COVID-19}

Gastrointestinal symptoms (GIS), as nausea, vomiting, abdominal pain and diarrhea, may be an early manifestation of SARS-CoV-2 infection (Wang et al., 2020a; Jin et al., 2020b; Huang et al., 2020). In fact, Huang et al. (2020) reported that GI involvement was present in $2-10 \%$ of patients with COVID-19. A systematic review evaluating GI involvement reported that the presence of GI symptoms had a great variability between 2 and $100 \%$; in particular, according to a pooled analysis, $16.1 \%$ presented GIS, $8.3 \%$ diarrhea, $12 \%$ nausea-vomiting and $4 \%$ abdominal pain (Pamolona et al., 2020). Sometimes, GI symptoms may precede respiratory ones (Wang et al., 2020a). Some studies suggest that the presence of GIS may indicate a higher probability of a severe course (Jin et al., 2020b; Guan et al., 2020). A higher percentage of diarrhea was observed in patients with severe disease $(5.8 \%)$ as compared to patients with a mild course of the disease (3.5\%) (Guan et al., 2020). As for other organs, also in the GI system the ACE2 receptor plays a fundamental role. This protein, in fact, is expressed in gastric, intestinal and colonic cells, promoting virus infection (Wan et al., 2020a). Therefore, once the virus infects the human intestinal epithelia, it can potentially propagate via fecal-oral route (Wang et al., 2020a; Guan et al., 2020; Pamolona et al., 2020). Interesting, viral RNA is detected in the stool for a longer time than in the respiratory system (Pan et al., 2020; Wu et al., 2020b). Consequently, it has been suggested that its detection in fecal samples should be considered as one of the routine diagnostic tests to guide decision making on hospital discharge and the lifting of isolation measures (Pamolona et al., 2020).

\section{A Multiorgan Disease: Cardiac and Cardiovascular Involvement of COVID-19 Infection}

The myocardial tissue and the cardiovascular (CV) system can be affected by COVID-19 infection through a variety of mechanisms with an important role played by inflammatory cytokines (ESC Guidance, 2020). The main CV manifestations observed are myocarditis, cardiomyopathies, arrhythmias, acute coronary syndromes (STEMI and NSTEMI) and venous thromboembolism which can lead to acute heart failure with cardiogenic shock (Clerkin et al., 2020). Their occurrence is associated with an increased risk of inhospital mortality, so it is crucial to identify these patients as soon as possible. In COVID19 infection, the severe hypoxia with subsequent increase of circulating catecholamines and the activation of $\mathrm{T}$ cells with an abnormal cytokines release (mainly IL-6 and IL-17) lead to oxidative stress and endothelial dysfunction with a consequent microangiopathy, vasospasm and myocardial ischaemia even in absence of coronary lesion. In addition, activation of the immune system leads to plaque instability in coronary arteries leading to coronary lesions, acute myocardial injury and arrhythmias as a consequence (Xu et al., 2020b; Madjid et al., 2020).

It has been reported a high prevalence of $\mathrm{CV}$ comorbidities (hypertension, atrial fibrillation (AF), DM, chronic heart failure (CHF) and kidney failure) in COVID patients. In a retrospective analysis carried out on 138 COVID-19 patients in Wuhan, one or more CV comorbidities were found in $50 \%$ of cases at least, rising $72 \%$ in severe cases (Zhou et al., 2020), with hypertension playing the main role (Wang et al., 2020a; Liu et al., 2020a; Zhou et al., 2020). This detail is important considering that ACE-2 receptor (located also in lungs, heart and vessels) is a part of the renin angiotensin system (RAS) and plays a main role in the development of COVID-19 CV involvement. SARS-CoV-2 infection appears to cause a loss of regulation of the RAS system, leading to upregulation of ACE-2 (Li, 2018; Walls et al., 2020; Zhou et al., 2020). This hypothesis might explain the datum of high prevalence of pre-existing hypertension in COVID-19 patients in ACEinhibitor (ACE-I) or angiotensin receptor blocker (ARBS) treatment, whose cardiac and vascular cells show a major expression of ACE-2 receptors compared to patients who do not assume these drugs (Walls et al., 2020; Zhou et al., 2020). In addition, ACE-2 up-regulation can also cause a direct myocardial injury secondary to an increased catecholamine level (Walls et al., 2020; Zhou et al., 2020).

As expected, common symptoms of $\mathrm{CV}$ involvement are represented by chest pain, breathlessness, tachycardia (ESC Guidance, 2020) and other varying signs and symptoms depending on the particular CV manifestation.

Myocardial injury might be due to myocarditis, characterized by infiltrates of interstitial mononuclear inflammatory cells (Xu et al., 2020b) and to a mismatch between oxygen supply and demand [type 2 classification according to the Fourth universal Definition (Thygesen et al., 2018)]. This second option may be secondary to the primary infection, hemodynamic and respiratory derangement.

A clinical and electrophysiological manifestation of myocarditis are arrhythmias, which have been reported in $16,7 \%$ of total patients and in $44 \%$ of ICU ones (Wang et al., 2020a). Sinus tachycardia is often linked to hypoxemia. The most common arrhythmia seems to be atrial fibrillation (new-onset or permanent with higher rate) which often appears in patients with 
electrolyte disturbances, ischaemia or acute cor pulmonale (Huang et al., 2020). New onset atrial fibrillation has been associated with higher mortality (Walkey et al., 2014; Boriani et al., 2019). There have been recognized different causes for arrhythmias genesis: first, via cross-talk between immune cells and myocardial cells, resulting in fibrosis that creates slow conduction areas; second, via leukocytes interacting with conduction system cells; third, via antibodies and cytokines causing ionic channels dysregulation. Another $\mathrm{CV}$ manifestation is heart failure (HF) which holds the worst presentation and prognosis (Li et al., 2020c; Zhou et al., 2020). It can be due to different mechanisms, such as acute myocardial infarction, myocarditis, acute kidney damage, hypovolemia, dehydration with hypovolemia, Takotsubo cardiomyopathy and ARDS with hypoxemia (Guan et al., 2020). In rare cases, myocarditis may have a fulminant presentation (with cardiac symptoms, haemodynamic deterioration, arrhythmias, elevation of biomarkers and suggesting imaging) (Liu et al., 2020b). HF could evolve in cardiogenic shock.

Laboratory tests in patients at high risk of mortality show high levels of Troponin T, IL-6 (Zhou et al., 2020) and DDimer (Walkey et al., 2014). In addition, the dynamic variations of Troponin I and proBNP have to be considered to identify high risk patients (Liu et al., 2020a). Indeed, persistent elevation and dynamic changes of Troponin I is an independent risk factor of mortality especially in patients with previous cardiovascular diseases (Liu et al., 2020a). BNP and NT-proBNP are usually elevated in patients with severe respiratory distress but they may also express cardiac injury in COVID-19 patients (Christ-Crain et al., 2008). Finally, if D-Dimer level is $>1,000 \mathrm{ng} / \mathrm{dl}$ it may indicate the presence of pulmonary embolism or disseminated intravascular coagulation in COVID-19 patients (Chen et al., 2020b).

In spite of what has been reported until now, multiple studies have found that the incidence of hospitalization for acute MI has decreased as much as $40-50 \%$ during the pandemic (De Filippo et al., 2020; Solomon et al., 2020).

This evenience could have two possible explanations: a patient avoidance of medical care secondary to the fear of being infected if hospitalized and redistribution of health care.

Treatment in patients with suspected SARS-CoV-2 infection and acute myocardial infarction, STEMI primary PCI might be postponed up to $60 \mathrm{~min}$ than the usual delay $(120 \mathrm{~min})$ in order to set all the protective measures; behind this delay, fibrinolysis should be considered. In acute myocardial infarction NSTEMI, cardiac CT should be considered for risk stratification in patients at intermediate and low risk. In patients with chronic coronary syndrome, aspirin should not be stopped because of its antiinflammatory effect (Rauch, 2020). Statin therapy may be interrupted considering the elevated liver enzymes in some COVID-19 patients and the possible rhabdomyolysis occurring as an adverse event of statins (Xu et al., 2020a).

Hypertension treatment with ACEIs and ARBS is a subject of debate. On one side these drugs could increase the expression of ACE2 receptors, raising the risk of COVID-19 infections (Hamming et al., 2004; Chen et al., 2020f; Hoffmann et al., 2020); on the other side, studies on animal models have shown a protective role of ARBs for lungs affected by some viruses (Rodrigues Prestes et al., 2017). Therefore, right now, there is no evidence of benefit or harm by those drugs, consequently they should not be discontinued or contraindicated (Poissy et al., 2020).

The incidence of pulmonary embolism in COVID-9 patients is reported to be high (Danzi et al., 2020; Poissy et al., 2020) and all COVID-19 patients admitted in hospital should start anticoagulation at prophylactic dose. If clinical and radiological findings confirm pulmonary embolism an appropriate treatment should be started, represented by thrombolysis for patients in shock, anticoagulation with unfractionated heparin, LMWH for stable patients. Regarding NOACs, an interaction with COVID drugs (such as lopinavir/ ritonavir via Cytochrome P450) has to be considered, causing an increased bleeding risk. Therefore, it is reasonable to consider to substitute NOAC with LMWH. Vitamin K antagonists should be discontinued and substituted with heparin and only considered in particular conditions such as mechanical valves implant (Guan Yap, 2003).

In COVID-19 patients with arrhythmias management and treatment are influenced by the clinical presentation and considering drug interactions. If allowed by haemodynamic conditions, antiarrhythmic drugs for AF and atrial flutter should be discontinued, due to interactions with azithromycin; therefore, minimal dosage of beta-blockers and calcium channel blockers should be preferred to gain rate control. Otherwise, in case of hemodynamic instability, electrical cardioversion does not seem effective in COVID-19 patients without treating underlying conditions (hypoxaemia, hypokalaemia, hypomagnesaemia, acidosis). When ventricular tachycardia, ventricular fibrillation, AF or atrial flutter occur in unstable patients' amiodarone can be considered the safest drug, due to his property to not cause QT dispersion. Sotalol and flecainide should not be administered.

QT prolongation, ventricular fibrillation, Torsades de Pointes (TdP) and sudden death are rarely due to a single administration of a drug (Chen et al., 2020e), and even when arrhythmias occur, they often disappear on their own. Hydroxychloroquine - which was mainly used in the early stages of the pandemics - causes significant QT prolongation in association with azithromycin, increasing the incidence of cardiac arrhythmias at 31\% (Zhao et al., 2020a). In patients with ventricular tachycardia and QT prolongation electrical, cardioversion and lidocaine represent the treatment of choice especially in patients with antiviral therapy. Drugs inducing QT prolongation should be stopped in patients with QTc $>500 \mathrm{~ms}$ (550 $\mathrm{ms}$ in presence of bundle branch blocks) or an increase $>60 \mathrm{~ms}$ from the baseline ECG; negative chronotropic drugs (beta-blockers, digoxin, ivabradine and calcium channel blockers), inducing bradycardia, prolong QT interval and their interactions with antiviral drugs need to be monitored.

\section{A Multiorgan Disease: Involvement of the Nervous System in COVID-19 Infection}

Coronaviruses (CoVs) (including also SARS-CoV-2) may invade the central nervous system (CNS) causing neurological diseases. 
Indeed, in order to gain cell entry, as it has already said, the virus binds to the ACE2 receptor which is also expressed in neurons, vascular endothelial and glial cells (Zhao et al., 2020a).

Two main routes through which the SARS-CoV-2 invades the nervous system have been proposed. Firstly, the dissemination of SARS-CoV-2 in the systemic circulation during an early or later phase can determine cerebral involvement (Baig et al., 2020). Secondly, increasing evidence shows that $\mathrm{CoV}$ may first invade peripheral nerve terminals and then gain access to the CNS via a synapse connected route ( $\mathrm{Li}$ et al., 2012; Li et al., 2020d). Through the trans-synaptic transfer, $\mathrm{CoV}$ can access to the brainstem (including the nucleus of the solitary tract and the nucleus ambiguous, which have a fundamental role in control of heart and lung' function) and this can worsen the dysfunction of the respiratory system (Netland et al., 2008). Nevertheless, this hypothesis has been debated due to the fact that brain failure usually gives a pattern of respiratory failure different from that seen in patients with COVID-19 (Turtle, 2020).

Together with the acute pneumonia and severe respiratory distress symptoms, many patients with COVID-19 complain of neurological disturbances, ranging from headache, hyposmia, ageusia, muscle pain to conscious disturbance, skeletal muscle injury and seizures. Mao et al. (2020) reported that 36\% of patients with a severe infection presented various neurologic manifestations involving CNS, PNS and skeletal muscles, mostly in old patients. Some of these neurologic symptoms might be foreseeable. Indeed, it is not uncommon that during an infective disease with high fever patients, especially the older, can manifest seizures. It has also been supposed that the severe hypoxia secondary to acute respiratory distress syndrome can enhance brain damage, being therefore the main reason for CNS involvement ( $\mathrm{Li}$ et al., 2020d). As far as epilepsy is concerned, clinicians have to be careful in choosing the correct treatment in COVID-19 patients. In fact, they have to consider pharmacological interactions between antiepileptic drugs (AEDs) and COVID-19 drugs (Liverpool Drug Interaction Group, http://www.covid19-druginteractions.org/). The same interactions can underlie seizures occurrence in epileptic patients even if in appropriate treatment. For example, cases reported the association of seizures with chloroquine therapy in systemic lupus erythematosus patients (Krzeminski et al., 2018).

Another neurologic manifestation is delirium. Moreover, as far as COVID-19 is concerned, the use of total-body personal protective equipment by medical staff, artificial light, closed wards, isolation and the absence of relatives can exacerbate and early arise delirium symptoms. Because its presence is associated with a devastating impact in outcomes for critically ill patients it should be promptly recognised and treated, according to current guidelines (Burry et al., 2019). Medical treatment for delirium includes not only supportive medical care and non-pharmacological intervention (which, as said before, in the contest of COVID ward can be difficult), but also antipsychotic drugs (e.g., haloperidol, olanzapine and quetiapine), which need to be used with caution due to the QTc prolongation and their interaction with COVID-19 drugs. Adequate pain identification and management, both in ICU and non-ICU setting, is crucial in order to prevent this manifestation which itself is a robust prognostic indicator of worse survival immediately (Kotfis et al., 2020).

Alongside, cerebrovascular system is also involved, as reported from the description of strokes (both in the setting of critical illness and during hypotension), coagulopathy and antiphospholipid antibodies in patients with COVID-19 (Zhang et al., 2020a) and acute hemorrhagic necrotizing encephalopathy (Poyiadji et al., 2020).

Neurologist should also expect the occurrence of post infectious syndromes such as acute disseminated encephalomyelitis and Guillain-Barré syndrome; the latter has been described even if, actually, it is not known if it is a consequence or a coincidence of SARS-CoV-2 infection, because real-time polymerase-chain-reaction assay of the CSF was negative for SARS-CoV-2 (Toscano et al., 2020; Zhao et al., 2020b). An important fact is the time of onset, which is essential to distinguish acute polyneuropathy with COVID-19 from critical illness neuropathy and myopathy, which usually appear later in the course of intensive care unit recovery.

In addition (and differently from SARS infection), olfactory and taste disorders hold a special interest due to the fact that they have been complained of during the incubation period while sudden onset sensorineural hearing loss has been reported during the course of the Covid-19 (Koumpa et al., 2020; Guan et al., 2020). An Italian cross-sectional survey described that $20 \%$ of patients presented olfactory and taste disorders before the hospital admission and only $13 \%$ during the hospital stay; interestingly patients with these symptoms were younger than those without (Giacomelli et al., 2020). The exact pathogenesis of ageusia and anosmia is still unknown: it might be due to a direct damage inside the olfactory bulb from the coronavirus or it might express only the classical congestion which is seen also in other viral infections. Interestingly, COVID-19 patients do not report nasal obstruction, differently from flu.

Apart from the suspected neurotropism of SARS-CoV-2, neurologists are concerned about the impact that the infection can have in patients with chronic neurologic diseases (e.g., previous stroke or other neurodegenerative disorder) or in patients with diseases that need immune-modulatory drugs (for example multiple sclerosis, myasthenia gravis, and neuromyelitis optica). In the latter case, if taking off immunemodulatory drugs is not advisable due to the catastrophic complications that this can set off, a possible intervention is to reassess treatment, both in dosage and in frequency of infusion (e.g., natalizumab and fingolimod for multiple sclerosis) (Bomprezzi and Pawate, 2014; Ghezzi, 2019). Time-dependent treatment of acute patients (namely for ischemic stroke) should also be reorganized with the aim to appropriately deal with it and to not increase disability in human beings (Khosravani et al., 2020).

Finally, even if it is known that the most severe neurologic complication occurs later and in more severe patients, with the growing knowledge about SARS-CoV-2 infection, big data, strenuous surveillance and global cooperation in recognizing other acute or post-infectious conditions are needed in order to deal with this challenge in the possible best way. 


\section{A Multiorgan Disease: Psychiatric Implications of COVID-19 Pandemic}

Maintaining a satisfactory mental health is a delicate balance that COVID-19 pandemic has undermined for the general population, health care workers, psychiatric patients and patients with COVID-19. During lockdown, the general population have experienced adverse psychological outcomes, such as anger, anxiety, boredom, confusion, fear, depression, emotional exhaustion, frustration, irritability, stress, avoidance behaviour and subthreshold symptoms of alcohol use disorder (Brooks et al., 2020; Pfefferbaum and North, 2020). Excessive concern for the pandemic with distressing somatic symptoms, detachment from others, post-traumatic stress disorder (PTSD), violence and suicidal ideation have also been described (Brooks et al., 2020; Pfefferbaum and North, 2020). Cross-sectional, selfreport surveys from January to april 2020 found that these symptoms were clinically significant present in up to $36 \%$ of adults (Wang et al., 2020c). Among healthcare workers-who are at high risk of exposure-psychiatric problems, such as significant psychological stress and acute and/or PTSD were more common in workers exposed to the virus than in those who were not (Kisely et al., 2020). In particular, anxiety was present in $12-20 \%$, depression in $15-25 \%$, insomnia in $8 \%$ and traumatic distress in 35-49\% (Rossi et al., 2020). Among patients with pre-existing psychiatric illness, infection with SARS-CoV-2 may exacerbate the pre-existing illness (Holmes et al., 2020). In addition to respiratory symptoms, COVID-19 patients may present neuropsychiatric syndrome in the acute phase of the illness, such as confusion and impaired consciousness, anxiety (35\%) and depression (28\%) (Rogers et al., 2020). The pathogenesis of psychiatric symptoms in previous healthy patients may include biologic and psychosocial factors. In fact, it is known that a combination of systemic infection, viral neurotropism and environmental stress facilitates induces development of psychiatric pathologies (Kisely et al., 2020). The "cytokine storm" secondary to viral infection, with high levels of circulating cytokine (IL-6, IL-1 $\beta$, IL-2, TNF- $\alpha$ ), is responsible of symptoms from apathy, motor inhibition to obsessive compulsive disorder, PTSD and schizophrenia (Steardo et al., 2020).

\section{A Multiorgan Disease: Ocular Involvement of COVID-19 Infection \\ Ocular Findings and Early Diagnosis}

According to recent reports, the only ocular clinical manifestation in patients with COVID-19 is acute viral conjunctivitis (Chen et al., 2020d; Wu et al., 2020a; Xia et al., 2020). SARS-CoV-2, as described by Wu et al. (2020a), can cause ocular involvement (32\% of 38 COVID-19 patients) and sometimes it may represent the first symptom of COVID-19 disease. The acute nonspecific viral conjunctivitis is characterized by conjunctival hyperemia, chemosis, epiphora, foreign body sensation, tearing and secretions. Chen et al. (2020d) identified in a patient with COVID-19 the signs of the viral conjunctivitis through slit lamp examination: bilateral moderate conjunctival injection, watery discharge, inferior palpebral conjunctival follicles and tender palpable preauricular lymph nodes. Treatment is the same as common viral conjunctivitis. Ocular findings were found in patients with high levels of leukocytes, neutrophils, procalcitonin, CRP and lactate dehydrogenase suggesting a correlation between ocular involvement and a severe disease form (Wu et al., 2020a).

Moreover, in patients with positive nasopharyngeal swabs for SARS-CoV-2 conjunctival swab was performed resulting positive only in a small part of patients (5\%) with conjunctivitis (Wu et al., 2020a). Additionally, Vinores et al. (2001) evaluated the tear and conjunctival secretions of COVID-19 patients with RT-PCR and only one swab on 30 tested positive for SARSCoV- 2 .

Based on these results, SARS-CoV-2 can cause ocular complications and in some cases may represent the first symptom of disease, even if is not a common manifestation. Early screening of SARS-CoV-2 in patients with conjunctivitis by searching the virus in the tears and conjunctival secretions may be conceivable. However, since the viral RNA levels in conjunctival specimens are dramatically lower than those in respiratory samples (Chen et al., 2020d), the conjunctiva might not serve as an ideal site for early diagnostic tests of SARS-CoV-2 infection.

Regarding other ocular complications, since coagulation disorders are also common in patients with SARS-CoV-2 infection, recent studies have linked coronavirus infection with retinal disorders, such as microangiopathy (Invernizzi et al., 2020b), hemolytic uremic syndrome with retinal vessel occlusion (Greenwood, 2015) and impending central retinal vein occlusion (Invernizzi et al., 2020a). Marinho et al. (2020) reported an alteration of inner retinal layers, such as hyperreflective lesions, based on optical coherence tomography (OCT) scans. However some authors suggested a possible misinterpretation of these findings, which may represent an individual variability of normal retinal vessels (Vavvas et al., 2020). The "Screening the retina in patients with COVID-19" study (SERPICO-19) showed the presence of retinal findings in patients with COVID-19, including retinal haemorrhages $(9.25 \%)$, cotton wools spots (7.4\%), drusen (11.1\%), dilated veins (27.7\%) and tortuous vessels (12.9\%) (Invernizzi et al., 2020b). However, concerns may be raised about the presence of bias in the sample enrolled, given the high prevalence of hypertension and diabetes in the cohort, which make these findings as possible incidental findings.

Further clinical studies are needed to evaluate the clinical spectrum of ocular diseases caused by SARS-CoV-2. Moreover, since ACE-2 is a cellular receptor for SARS-CoV-2 (Lu et al., 2020b) detected in the human retina (Wagner et al., 1996; Senanayake et al., 2007), a possible involvement of the internal ocular structures such as the retina cannot be excluded.

\section{Transmission Through the Ocular Surface}

The role of the eye in transmitting human SARS-CoV-2 is still under discussion.

Some authors have underlined that the transmission through the ocular surface should not be underestimated, since infectious droplets can easily contaminate the human conjunctival epithelium (Lu et al., 2020a). The detection of the SARS-CoV2 in tears and conjunctival secretions confirms this hypothesis (Chen et al., 2020d; Wu et al., 2020a; Xia et al., 2020). However, 
the low prevalence of SARS-CoV-2 in the ocular surface of patients with conjunctivitis and the absence in patients without ocular signs could mean that tears and conjunctival secretions of COVID-19 patients are not a common infectious route for SARS-CoV-2. Nevertheless, the risk of transmission could not be completely eliminated. As reported by Chen et al. (Chen et al., 2020d) the viral loads in conjunctival specimens of COVID-19 patients gradually decrease over time with less potential for transmissibility accompanied by improvement of the ocular symptoms. Therefore SARS-CoV-2 in conjunctival specimens may represent a source of spread, especially in the acute stage of ocular complications characterized by high viral load. Qing et al. (2020) stressed the role of lacrimal drainage as a route of SARS-CoV-2 transmission. Anatomically, the ocular surface and upper respiratory tract are connected by nasolacrimal duct. Therefore, it is possible that the virus reaches the tears through droplets, passing through the nasolacrimal ducts and then into the respiratory tract.

\section{Precautionary Measures Needed for Physicians}

Containing viral spread is the primary means by which we protect people from newly emerging infections (Sommer, 2020). Ophthalmologists are a high-risk category, not only because they have close contact with patients during the examination (conjunctival, tear secretions and aerosol secretions), but also because their daily outpatient clinic and emergency lists have a high patient volume (Lai et al., 2020a; Romano et al., 2020). In order to minimize transmission of COVID-19, some precautionary measures are mandatory for physicians when coming into contact with suspected or confirmed cases of COVID-19 (Lai et al., 2020a; Lai et al., 2020b; Li et al., 2020a; Mungmungpuntipantip and Wiwanitkit, 2020; Romano et al., 2020). These measures include:

- Protection of health workers with appropriate PPE: protective eyewear can prevent direct inoculation of respiratory droplets through the conjunctiva, and also indirect contamination of conjunctiva through inadvertent eye rubbing with a contaminated hand. During eye examination, a self-made transparent polycarbonate protector mounted to the slit lamp offers a physical barrier between the patient and physician (Wan et al., 2020b). Non-contact air-puff tonometry has been associated with a micro-aerosol formation (Wan et al., 2020b); therefore, other ways of intraocular pressure measurement, such as i-Care tonometry or Goldmann applanation tonometry should be used instead

- Appropriate environmental control: important to reduce the concentration of virus on contaminated surfaces. Considering that coronavirus can persist on inanimate surfaces up to 9 days (Kampf et al., 2020), it is crucial to perform an appropriate sanitation of the potentially contaminated environment. Equipment must be cleaned and disinfected after every clinic session.

- Reorganization of the workflow to minimize the risk of cross infections: non-urgent consultations and operations should be delayed. Urgent consultations (ocular trauma, acute glaucoma, retinal detachment, alkali chemical injury, etc.) should be attended with adequate PPE.

\section{Management of COVID-19 Patients in the Intensive Care Unit}

Hospitalization in ICU is required in about 5\% of COVID-19 patients who can rapidly progress to ARDS, MOF, sepsis and septic shock. The primary reason for ICU admission is the patient's need for endotracheal intubation and mechanical ventilation (Grasselli et al., 2020).

COVID-19 patients mainly are affected by respiratory system failure whereas other organ functions are less involved. The most frequent clinical evolution during the hyperinflammatory phase is the development of ARDS. Nevertheless, not all the cases of severe ARF are considered as typical ARDS. For this reason, Marini et al., called ARDS COVID related as C-ARDS. There are differences between COVID-19-related ARDS and ARDS caused by other factors as defined by Berlin criteria, and, therefore, there are also differences in the treatment ( $\mathrm{Li}$ and $\mathrm{Ma}, 2020)$.

ARDS can be classified on Berlin criteria in (The ARDS Definition Task Force, 2012):

- Mild ARDS: $200 \mathrm{mmHg}<\mathrm{PaO} 2 / \mathrm{FiO} 2 \leq 300 \mathrm{mmHg}$ (with PEEP or CPAP $\geq 5 \mathrm{cmH} 2 \mathrm{O}$, orunventilated).

- Moderate ARDS: $100 \mathrm{mmHg}<\mathrm{PaO} 2 / \mathrm{FiO} 2 \leq 200 \mathrm{mmHg}$ (with PEEP $\geq 5 \mathrm{cmH} 2 \mathrm{O}$, or unventilated).

- Severe ARDS: $\mathrm{PaO} 2 / \mathrm{FiO} 2 \leq 100 \mathrm{mmHg}$ (with PEEP $\geq 5$ $\mathrm{cmH} 2 \mathrm{O}$, or unventilated). When $\mathrm{PaO} 2$ is not available, $\mathrm{SpO} 2 / \mathrm{FiO} 2 \leq 315$ suggests ARDS (including unventilated patients) (Circolare Ministeriale, 2020; World Health Organization, 2020a; European Center for Disease Prevention and Control, 2020; Ranieri, 2012; Arabi, 2020; World Health Organization, 2020b; Wax, 2020; BPCPDTA, 2020).

\section{Invasive Mechanical Ventilation}

Patient selection for invasive mechanical ventilation (IVM) is clinically based on severe hypoxemia and dyspnea in patients previously treated by non invasive ventilation (NIV) or continuous positive airway pressure (CPAP) and, most of the time, the timing of IVM is very important.

Most of the patients in intensive care units shows the same clinical findings of acute respiratory distress syndrome but in some cases they do not have the same response to protective ventilation.

Mechanical ventilation in COVID-19 patients results in different respiratory patterns which can be challenging.

In april 2020, Marini and Gattinoni (2020) laid out a conceptual model to underline the role of a possible endothelial damage that disrupts pulmonary vasoregulation leading to a ventilation-perfusion mismatch and thrombogenesis. The endothelial damage could clinically translate into a particular pattern characterized by hypoxemia with normal pulmonary compliance, findings uncommon for ARDS patients (Gattinoni et al., 2020a).

This discrepancy between pulmonary compliance and hypoxemia may lead to different ventilation settings based on 
the interactions between different factors: the phase of infection, the host response, and the time of NIV/CPAP.

The result of this interaction lead to a time-related disease spectrum within two primary "phenotypes" named (Gattinoni et al., 2020b): Type "L" patients, with Low elastance, Low ventilation to perfusion ratio, low lung weight, and low recruitability; IVM in this type of patients is aimed to minimize pulmonary stress, reduce hypoxemia and interrupt the vicious cycle that may lead to a ventilator-induced lung injury (VILI) (Marini and Gattinoni, 2020); Once intubated and sedated, these patients, present a good tolerance to Tidal Volume (TV) 7-8 ml/kg and they are low responsive to PEEP; a worsening of clinical symptoms and signs might be related with the negative intrathoracic pressure associated and the increased tidal volume in spontaneous breathing (Gattinoni et al., 2020a). Also, prone positioning should be used only as a rescue maneuver. Type "L" patients can evolve towards the phenotype " $H$ ". Type " $H$ " patients are characterized by High elastance, High right-to-left shunt, High lung weight, and High recruitability. Type $\mathrm{H}$ patients should be treated as severe ARDS, including protective lung ventilation setting and higher PEEP, prone positioning and extracorporeal support (Brochard et al., 2017). The aim of mechanical ventilation in Type $\mathrm{H}$ patients is to minimize lung stress and ventilationperfusion mismatch (Marini and Gattinoni, 2020).

Type $\mathrm{L}$ and Type $\mathrm{H}$ patients are best identified by CT scan and are affected by different pathophysiological mechanisms. Considering these assumptions, invasive ventilatory approach should be evaluated and above all, differentiated both in acute respiratory failure and in post acute phase. A clinical protocol should be applied in each COVID-19 center in order to differentiate patients that need invasive ventilation treatment and, above all, to choose which patients would benefit from invasive ventilation in relation to the stage of the disease and patient phenotype (Marini and Gattinoni, 2020).

\section{Hemodynamic Support in Septic Shock}

In septic COVID-19 critical patients, the illness is characterized by an organ dysfunction caused by a dysregulated response of the host to suspected or certain infection, with Sequential [Sepsisrelated] Organ Failure Assessment (SOFA) score of two points or more (Singer et al., 2016). The signs of organ dysfunction include altered mental status, difficult or rapid and superficial breathing, low oxygen saturation, oligoanuria, tachycardia, weak pulsations, cold extremities or hypotension, skin alterations, laboratory findings of coagulation alterations, thrombocytopenia, acidosis, elevated lactates or hyperbilirubinemia.

These COVID-19 critical patients may evolve to septic shock, defined as hypotension unresponsive to volume expansion, which requires vasopressors to maintain $\mathrm{MAP} \geq 65 \mathrm{mmHg}$ and serum lactate level $\geq 2 \mathrm{mmol}$.

The frequency of septic shock varies from 20 to $35 \%$ in ICU among patients affected by COVID-19 (Wang et al., 2020a; Yang et al., 2020). In some studies, the development of fulminant myocarditis has been possibly the dominant reason for $40 \%$ of
ICU deaths (Ruan et al., 2020). Other studies also advise that risk factors to consider are older age comorbidities like diabetes and cardiovascular diseases including hypertension, lower lymphocyte count, higher D-dimer level, or possible cardiac injuries (Wang et al., 2020a; Yang et al., 2020).

The two mainstays of hemodynamic treatment have been increasing intravascular volume with fluids and by counteracting hypotension, as well as low cardiac output with vasoactive drugs with varying inotropic properties. The use of dynamic assessment should guide fluid therapy and it may reduce mortality, duration of mechanical ventilation and ICU length of stay (LOS). Within their respective limitations, the functional hemodynamic parameters which should be used to guide fluid therapy as part of goal directed therapy strategies are parameters such as stroke volume variation (SVV), pulse pressure variation (PPV). In contrast, assessing fluid responsiveness with passive leg raising manoeuvre, central venous pressure (CVP), and mean arterial pressure (MAP) may result in false-negative cases.

Moreover, early lactate clearance-directed therapy (even though a high lactate level does not always imply hypovolemia) may be linked to a reduction in mortality and LOS in ICU, when compared to the central venous oxygen saturation (ScVO2) guided therapy (Pan et al., 2019).

Fluid therapy used to correct circulatory failure is elementary and cheap. However, there are no indications that the fluids should be carefully prescribed in order to maximize their result or limit their side-effects. The use of dynamic assessment to guide fluid therapy has reduced both mortality and duration of mechanical ventilation (Bentzer et al., 2016; Bednarczyk et al., 2017). Although a review that compared restricted to liberal fluid volumes in the initial resuscitation of patients with sepsis has not found any statistically significant variation in mortality or serious adverse events (Meyhoff et al., 2020), we recommended an initial conservative approach to fluid resuscitation in COVID-19 patients with shock. There is no outcome that preferred the use of colloids when compared to the use of crystalloids in critically ill patients (Lewis et al., 2018). Knowing that some colloids are harmful, they are more expensive, and their availability can be limited. Therefore, we recommend the use of crystalloids for fluid resuscitation in COVID-19 patients with shock, using buffered/balanced crystalloids over the unbalanced ones, instead of choosing hydroxyethyl starches, gelatines, or dextrans. Also, the regular use of albumin for initial resuscitation is not linked to improved outcomes (Lewis et al., 2018).

The best first-line treatment on COVID-19 patients with shock is norepinephrine, alternatively, vasopressin or epinephrine should be considered (Gamper et al., 2016; Moller et al., 2016). Dopamine should be avoided, as it increases the arrhythmias risks. The targeted therapy based on the standard of care MAP targeted of $60-65 \mathrm{mmHg}$, titrating the vasoactive agents is recommended (Moller et al., 2018); moreover, it is also suggested to add a second-line agent (vasopressin) if the target is not achieved by norepinephrine itself (Honarmand et al., 2020). Furthermore, based on a physiological reason, the use of dobutamine in COVID-19 
patients with shock and cardiac dysfunction, should be considered (Moller et al., 2018).

If available, Guideline recommends that all patients who require vasopressors have an arterial catheter placed as soon as practical.

For adults with COVID-19 and refractory shock, it is recommended the use of low-dose corticosteroid therapy ("shock-reversal") over no corticosteroid. A typical corticosteroid regimen in septic shock is intravenous hydrocortisone $200 \mathrm{mg}$ per day administered either as an infusion or intermittent doses. The duration of hydrocortisone therapy is usually a clinical decision (https://www.covid19treatmentguidelines.nih.gov/critical-care/ hemodynamics/; Rhodes et al., 2016; Bednarczyk et al., 2017).

\section{Patient's Step-Down From the Intensive Care Unit} COVID-19 patients may be stepped-down from ICU to medical wards (or ad-hoc COVID-19 wards) when they show a non-critical condition and an improvement of clinical features and radiologic findings. The aims of the non-ICU department include the weaning from oxygen or from the use of CPAP/NIV or helmet CPAP, the prosecution of treatment of bacterial superinfection eventually contracted in ICU, the prevention of possible complication of Sars-CoV-2 infection, the follow-up of patients until hospital discharge. Whenever possible, patients should be discharged from hospital after recovery confirmed by the double consecutive negative swabs (Procedura Regionale Nuovo Coronavirus Sars, 2020).

Most patients admitted to ICU have a prolonged length of stay (on average 3 weeks), therefore requiring adequate rehabilitation once stepped-down to medical wards (Procedura Regionale Nuovo Coronavirus Sars, 2020). Despite the progressive clinical improvement of the respiratory disease, prolonged bed rest syndrome and invasive mechanical ventilation sequelae (such as iatrogenic post-intubation dysphagia, tracheostomy management) have been reported. Hence, it is advisable to promote a rehabilitation program into the non-ICU department (aerobic exercise, strength training for muscle weakness, bronchial clearance techniques in hyper-secretive patients) and to direct the frailest patients with severe sequelae to rehabilitation units (Brugliera et al., 2020).

\section{Hospital Discharge}

Different rules have been developed to decide whether or not patients should be discharged home after hospitalization. Generally, independently from the ICU or non-ICU stay, two main strategies are indicated (CDC Discontinuation, 2020):

Test-based strategy:

Resolution of fever without the use of fever-reducing medications and improvement in respiratory symptoms (e.g., cough, shortness of breath), and negative results of a COVID-19 molecular assay for detection of SARS-CoV-2 RNA from at least two consecutive nasopharyngeal swab specimens collected $\geq 24 \mathrm{~h}$ apart (total of two negative specimens).

Non-test-based strategy:
At least 3 days $(72 \mathrm{~h})$ have passed since recovery defined as resolution of fever without the use of fever-reducing medications and improvement in respiratory symptoms (e.g., cough, shortness of breath); and at least 7 days have passed since symptoms first appeared.

It is therefore specified, in accordance with what is outlined by the CDC, that meeting criteria for discontinuation of transmissionbased precautions is not a prerequisite for discharge.

In Italy, a COVID-19 patient is considered cured after the resolution of symptoms and two negative tests for SARS-CoV-2 at 24-h intervals. In patients who clinically recover before 7 days after onset, an interval of 7 days between the first and the final test is recommended. For virus clearance it is defined as a negative viral RNA from body fluids of symptomatic and asymptomatic patients, accompanied by the appearance of specific IgG (Ministero della salute, 2020).

As a precautionary measure, in several countries patients are told to self-isolate once discharged from the hospital, even in case of swab negativity (Ministero della salute, 2020). Serological testing performed at time of discharge can provide important information on the immune response of infected individuals (Ministero della salute, 2020).

\section{Nursing Role During COVID-19}

In the setting of hospital care, all healthcare workers, including nurses, technicians, and drivers have played an important and variegated role during pandemic months. In regard to nurses, they helped doctors not only in treating COVID-19 patients, but also in supplying nosocomial infection prevention and surveillance (Chen et al., 2020c). Moreover, they provided health and screening education and support for the general population and high-risk categories (Chen et al., 2020c).

\section{CONCLUSIONS}

The COVID-19 pandemic has challenged healthcare systems on a global scale, requiring that hospitals make a significant effort to repurpose their services and healthcare delivery. As the pandemic has progressed, clinicians have developed a greater understanding of the multifaceted nature of COVID-19 disease, as well as its myriad presentations not limited to the respiratory tract. Given the complex nature of this new condition, assessment and treatment of hospitalized patients should involve the expertise of a range of specialties. Knowledgesharing between specialists is undoubtedly required to determine the timing and setting in which proven treatments should be administered to manage patients suffering from COVID-19.

\section{AUTHOR CONTRIBUTIONS}

All authors contributed equally to the review of literature and to the production of this manuscript. 


\section{REFERENCES}

Ambrose, H.-T. F., Wong, H. Y. F., Lam, H. Y. S., Leung, S. T., Chin, T. W.-Y., Lo, C. S. Y., et al. (2019). Frequency and distribution of chest radiographic findings in COVID-19 positive patients. Radiology 11, 201160. doi:10.1148/radiol. 2020201160

Antonelli, M., Conti, G., and Moro, M. L. (2001). Predictors of failure of noninvasive positive pressure ventilation in patients with acute hypoxemic respiratory failure: a multicenter study. Intens. Care Med. 27 (11), 1718-1728. doi:10.1007/s00134001-1114-4

Arabi, Y. M. (2020). Critical care management of adults with community-acquired severe respiratory viral infection. Intens. Care Med. 46 (2), 315-323. doi:10. 1007/s00134-020-05943-5

Asperges, E., Novati, S., Muzzi, A., Biscarini, S., Sciarra, M., Lupi, M., et al. (2020). The COVID19 IRCCS San Matteo Pavia Task Force, rapid response to COVID19 outbreak in Northern Italy: how to convert a classic infectious disease ward into a COVID-19 response centre. J. Hosp. Infect. 14, 64-69. doi:10.1016/j.jhin. 2020.03.020

Baig, A. M., Khaleeq, A., Ali, U., and Syeda, H. (2020). Evidence of the COVID-19 virus targeting the CNS: tissue distribution, host-virus interaction, and proposed neurotropic mechanisms. ACS Chem. Neurosci. 7, 22-59. doi:10. 1021/acschemneuro.0c00122

Bednarczyk, J. M., Fridfinnson, J. A., Kumar, A., Blanchard, L., Rabbani, R., Bell, D., et al. (2017). Incorporating dynamic assessment of fluid responsiveness into goal-directed therapy: a systematic review and meta-analysis. Crit. Care Med. 45, 1538-1545. doi:10.1097/ccm.0000000000002554

Beigel, J. H., Tomashek, K. M., and Dodd, L. E. (2020). Remdesivir for the treatment of covid-19 - final report [published online ahead of print, 2020 oct 8]. N. Engl. J. Med. 36, 72-78. doi:10.1056/NEJMoa2007764

Bentzer, P., Griesdale, D. E., Boyd, J., MacLean, K., Sirounis, D., and Ayas, N. T. (2016). Will this hemodynamically unstable patient respond to a bolus of intravenous fluids?. J. Am. Med. Assoc. 316, 1298-1309.

Bernheim, A., Mei, X., Huang, M., Yang, Y., Fayad, Z. A., Zhang, N., et al. (2020). Chest CT findings in coronavirus disease-19 (COVID-19): relationship to duration of infection. Radiology 295 (3), 200463. doi:10.1148/radiol. 2020200463

Bomprezzi, R., and Pawate, S. (2014). Extended interval dosing of natalizumab: a twocenter, 7-year experience. Therap. Adv. Neurol. Disord. 7(5), 227-231. doi:10.1177/1756285614540224

Boriani, G., Fauchier, L., Aguinaga, L., Beattie, J. M., Blomstrom Lundqvist, C., et al. (2019). European heart rhythm association (EHRA) consensus document on management of arrhythmias and cardiac electronic devices in the critically ill and post-surgery patient, endorsed by heart rhythm society (HRS), asia pacific heart rhythm society (APHRS), cardiac arrhythmia society of southern africa (CASSA), and Latin American heart rhythm society (LAHRS). Europace 21 (1), 7-8. doi:10.1093/europace/euy110

BPC-PDTA (2020). BPC-PDTA GdS Sepsi e infezioni SIAARTI (Società Italiana Anestesia Rianimazione e Terapia Intensiva). Available from: http://www.siaarti. it/SiteAssets/News/COVID19\%20\%20documenti\%20SIAARTI/SIAARTI\%20$\% 20$ Covid $19 \% 20 \% 20$ Percorso\%20Area\%20Critica.pdf (Accessed October 10, 2020).

Brochard, L., Slutsky, A., and Pesenti, A. (2017). Mechanical ventilation to minimize progression of lung injury in acute respiratory failure. Am. J. Respir. Crit. Care Med. 195 (4), 438-442. doi:10.3410/f.726737645.793572541

Brooks, S. K., Webster, R. K., Smith, L. E., Woodland, L., Wessely, S., Greenberg, N., et al. (2020). The psychological impact of quarantine and how to reduce it: rapid review of the evidence. Lancet 395 (10227), 912. doi:10.2139/ssrn.3532534

Brugliera, L., Spina, A., and Castellazzi, P. (2020). Rehabilitation of COVID-19 patients. J. Rehabil. Med. 52 (4), jrm00046. doi:10.2340/165019772678

Burry, L., Hutton, B., and Williamson, D. R. (2019). Pharmacological interventions for the treatment of delirium in critically ill adults. Cochrane Database Syst. Rev. 9 (9), CD011749. doi:10.1002/14651858.CD011749.pub2

Caputo, N. D., Strayer, R. J., and Levitan, R. (2020). Early self-proning in awake, non-intubated patients in the emergency department: a single ED's experience during the COVID-19 pandemic. Acad. Emerg. Med. 4, 54-57. doi:10.1111/acem.13994
Carron, M. (2020). Complications of non-invasive ventilation techniques: a comprehensive qualitative review of randomized trials. Br. J. Anaesth. 110 (6), 896-914. doi:10.1093/bja/aet070

Caruso, D., Zerunian, M., Polici, M., Pucciarelli, F., Polidori, T., Rucci, C., et al. (2020). Chest CT features of COVID-19 in rome. Italy Radiol. 11, 201237. doi:10.1148/radiol.2020201237

Circolare Ministeriale. (2020). Circolare Ministeriale n 5443 del 22/02/2020. Available from: http://www.ordinedeimedicicz.it/index.php/post/270/circolare-ministerialen-5443-del-22-02-2020-covid-2019-nuove-indicazioni-e-chiarimenti-177

Chen, T.-Y., Lai, H.-W., Hou, I.-L., Lin, C.-H., Chen, M.-K., Chou, C.-C., et al. (2020a). Buffer areas in emergency department to handle potential COVID-19 community infection in Taiwan, Travel Med. Infect. Dis. 4, 27. doi:10.1016/j. tmaid.2020.101635

Chen, N., Zhou, M., Dong, X., Qu, J., Gong, F., et al. (2020b). Epidemiological and clinical characteristics of 99 cases of 2019 novel coronavirus pneumonia in Wuhan, China: a descriptive study. Lancet 395 (10223), 507-513. doi:10.1016/ s0140-6736(20)30211-7

Chen, S.-C., Lai, Y.-H., and Tsay, S.-L. (2020c). Nursing perspectives on the impacts of COVID-19. J. Nurs. Res.: June 28 (3), e85. doi:10.1097/NRJ. 0000000000000389

Chen, L., Liu, M., Zhang, Z., Qiao, K., Huang, T., Chen, M., et al. (2020d). Ocular manifestations of a hospitalised patient with confirmed 2019 novel coronavirus disease. Br. J. Ophthalmol. 4, 23-33. doi:10.1136/bjophthalmol2020-316304

Chen, Z., Hu, J., Zhang, Z., and Jiang, S. (2020e). Efficacy of hydroxychloroquine in patients with COVID-19: results of a randomized clinical trial. Facul. Opin. Post-Publ. Peer Rev. Biomed. Lit. 22, 20040758. doi:10.1101/2020.03.22. 20040758

Chen, Y., Guo, Y., Pan, Y., and Zhao, Z. J. (2020f). Structure analysis of the receptor binding of 2019nCoV. Biochem. Biophys. Res. Commun. 19, 231-245. doi:10. 2210/pdb1xy2/pdb

Chiumello, D., Mongodi, S., Algieri, I., et al. (2018). Assessment of lung aeration and recruitment by $\mathrm{CT}$ scan and ultrasound in acute respiratory distress syndrome patients. Crit. Care Med. 46 (11), 17611768. doi:10.1097/CCM. 0000000000003340

Christ-Crain, M., Breidthardt, T., Stolz, D., Zobrist, K., Bingisser, R., Miedinger, D., et al. (2008). Use of B-type natriuretic peptide in the risk stratification of community-acquired pneumonia. J. Intern. Med. 264 (2), 166-176. doi:10.1111/ j.1365-2796.2008.01934.x

Clerkin, K. J., Fried, J. A., Raikhelkar, J., Sayer, G., Griffin, J. M., Masoumi, A., et al. (2020). COVID-19 and cardiovascular disease. Circulation 141 (20), 1648-1655. doi:10.1161/CIRCULATIONAHA.120.046941

Danzi, G. B., Loffi, M., Galeazzi, G., and Gherbesi, E. (2020). Acute pulmonary embolism and COVID-19 pneumonia: a random association? Eur. Heart J. 11, 27. doi:10.1093/eurheartj/ehaa254

De Filippo, O., D’Ascenzo, F., Angelini, F., Bocchino, P. P., Conrotto, F., Saglietto, A., et al. (2020). Reduced rate of hospital admissions for ACS during COVID-19 outbreak in northern Italy. N. Engl. J. Med. 383 (1), 88. doi:10.1056/ NEJMc2009166

Di Pietro, S., Mascolo, M., and Falaschi, F. (2020). Lung-ultrasound objective structured assessment of technical skills (LUS-OSAUS): utility in the assessment of lungultrasound trained medical undergraduates [published online ahead of print, 2020 Apr 8]. J Ultrasound. 44, 83-94. doi:10.1007/ s40477-020-00454-x10.1007/s40477-02000454-x

CDC Discontinuation. (2020). Of transmission-based precautions and disposition of patients with COVID-19 in healthcare settings (interim guidance). Available from: https://www.cdc.gov/coronavirus/2019-ncov/hcp/dispositionhospitalizedpatients.html.

ESC Guidance. (2020). ESC Guidance for the Diagnosis and Management of CV Disease during the COVID-19 Pandemic. Available from: https://www.escardio. org/Education/COVID19-and-Cardiology/ESC-COVID-19-Guidance.

European Center for Disease Prevention and Control. (2020). Outbreak of novel coronavirus disease 2019 (COVID-19): increased transmission globally-fifth update. Available from: https://www.ecdc.europa.eu/en/publicationsdata/rapidrisk-assessment-outbreak-novel-coronavirus-disease-2019-covid-19increased.

European Centre for Disease Prevention and Control (ECDC). (2020a). Case definition and European surveillance for COVID-19. Available from: https:// 
www.ecdc.europa.eu/en/case-definition-and-european-surveillance-humaninfection-novelcoronavirus-2019-ncov.

European Centre for Disease Prevention and Control (ECDC). (2020b). Public health management of persons, including healthcare workers, having had contact with COVID-19 cases in the European Union. Available from: https://www.ecdc. europa.eu/en/publications-data/public-health-management-personsincludinghealth-care-workers-having-had-contact.

European Centre for Disease Prevention and Control (ECDC). (2020c). Resource estimation for contact tracing, quarantine and monitoring activities in the EU/ $E E A$. Available from: https://www.ecdc.europa.eu/en/publications-data/resourceestimation-contact-tracing-quarantine-andmonitoring-activities-covid-19.

Fausto, J., Hirano, L., Lam, D., Mehta, A., Mills, B., Owens, D., et al. (2020). Creating a palliative care inpatient response plan for COVID19-the UW medicine experience. J. Pain Symptom Manag. 14, 53-59. doi:10.1016/j. jpainsymman.2020.03.025

FADOI (2020). Available from: https://www.fadoi.org/wp-content/uploads/2020/ 04/FADOI_Guida-clinico-praticacovid-19_rev5.pdf

Zhou, F., Ting, Y., and Du, R. (2020). Clinical course and risk factors for mortality of adult in patients with COVID-19 in Wuhan, China: a retrospective cohort study. Lancet 395, 1054-1062. doi:10.1016/S0140-6736(20)30566-3

Fouladseresht, H., Doroudchi, M., and Rokhtabnak, N. (2020). Predictive monitoring and therapeutic immune biomarkers in the management of clinical complications of COVID-19. Cytokine Growth Factor Rev. 14, 39. doi:10.1016/j.cytogfr.2020.10.002

Gagliano, A., Villani, P. G., and Francesca, M. C. (2020). COVID-19 epidemic in the middle province of northern Italy: impact, logistics, and strategy in the first line hospital. Disaster Med. Public Health Prep. 7, 1-5. doi:10.1017/dmp.2020. 51

Gamper, G., Havel, C., Arrich, J., Losert, H., Pace, N. L., Mullner, M., et al. (2016). Vasopressors for hypotensive shock. Cochrane Database Syst. Rev. 2, CD003709. doi:10.1016/j.annemergmed.2012.08.028

Gattinoni, L., Chiumello, D., Caironi, P., Busana, M., Romitti, F., Brazzi, L., et al. (2020b). COVID-19 pneumonia: different respiratory treatments for different phenotypes? Intens. Care Med. 46 (6), 1099-1102. doi:10.1007/s00134-02006033-2.182

Gattinoni, L., Chiumello, D., and Rossi, S. (2020a). COVID-19 pneumonia: ARDS or not? Crit. Care 24 (1), 154. doi:10.1186/s13054-020-02880-z

Ghezzi, A. (2019). Long-term effect of immediate versus delayed fingolimod treatment in young adult patients with relapsing-remitting multiple sclerosis: pooled analysis from the FREEDOMS/FREEDOMS II trials [published correction appears in neurol ther. 2020 Feb 14;:]. Neurol Ther 8 (2), 461-475. doi:10.1007/s40120-019-0146-z

Giacomelli, A., Pezzati, L., and Conti, F. (2020). Self-reported olfactory and taste disorders in SARS-CoV-2 patients: a cross-sectional study. Clin. Infect. Dis. 4, 17. doi:10.1093/cid/ciaa330

Global Surveillance. (2020). Global Surveillance for human infection with novel coronavirus (2019-nCoV) and The World Health Organisation. Available from https://www.who.int/publicationsdetail/global-surveillance-for-human-infectionwithnovel-coronavirus-(2019-ncov) (Accessed January 21, 2020).

Grasselli, G., Pesenti, A., and Cecconi, M. (2020). Critical care utilization for the COVID-19 outbreak in lombardy, Italy: early experience and Forecast during an emergency response. J. Am. Med. Assoc. 323 (16), 1545-1546. doi:10.1001/ jama.2020.4031

Greenwood, G. T. (2015). Case report of atypical hemolytic uremic syndrome with retinal arterial and venous occlusion treated with eculizumab. Int. Med. Case Rep. J. 8, 235-239. doi:10.2147/imcrj.s90640

Guan, W. J., Ni, Z. Y., Hu, Y., Liang, W. H., Ou, C. Q., He, J. X., et al. (2020). China medical treatment expert group for $\mathrm{C}$. Clinical characteristics of coronavirus disease 2019 in China. N. Engl. J. Med. 12, 272-284. doi:10.1056/ NEJMoa2002032

Guan Yap, Y. (2003). Drug induced QT prolongation and torsades de pointes. Heart 89 (11), 1363-1372. doi:10.1136/heart.89.11.1363

Li, G. (2018). Assessing ACE2 expression patterns in lung tissues in the pathogenesis of COVID-19. J. Autoimmun. 92, 12-33. doi:10.1016/j.jaut. 2020.102463

Hamming, I., Timens, W., Bulthuis, M. L., Lely, A. T., Navis, G., and van Goor, H. (2004). Tissue distribution of ACE2 protein, the functional receptor for SARS coronavirus. A first step in understanding SARS pathogenesis. J. Pathol. 203 (2), 631-637. doi:10.3410/f.722405811.793572965

Harari, S. A., Vitacca, M., and Blasi, F. (2004). Managing the respiratory care of patients with COVID-19. London: ITS-AIPO-SIC.

Heimfarth, L., Serafini, M. R., Martins-Filho, P. R., Quintans, J. D. S. S., and Quintans-Júnior, L. J. (2020). Drug repurposing and cytokine management in response to COVID-19: a review. Int. Immunopharm. 88, 106947. doi:10.1016/j. intimp.2020.106947

Helms, J., Tacquard, C., and Severac, F. (2020). High risk of thrombosis in patients with severe SARS-CoV-2 infection: a multicenter prospective cohort study [published online ahead of print, 2020 May 4]. Intens. Care Med. 2, 1-10. doi:10. 1007/s00134-020-06062-x

Hendin, A., La Rivière, C. G., Williscroft, D. M., O'Connor, E., Hughes, J., and Fischer, L. M. (2020). Endof-life care in the emergency department for the patient imminently dying of a highly transmissible acute respiratory infection (such as COVID-19) [published online ahead of print, 2020 Mar 26]. CJEM 30, 1-4. doi:10.1017/cem.2020.352

Hoffmann, M., Kleine-Weber, H., Schroeder, S., Kruger, N., Herrler, T., Erichsen, S., et al. (2020). SARS-CoV-2 cell entry depends on ACE2 and TMPRSS2 and is blocked by a clinically proven protease inhibitor. Cell 181, 271-280. doi:10. 1016/j.cell.2020.02.052

Holmes, E. A., O'Connor, R. C., Perry, V. H., Tracey, I., Wessely, S., Arseneault, L., et al. (2020). Multidisciplinary research priorities for the COVID-19 pandemic: a call for action for mental health science. Lancet Psych. 7 (6), 547. doi:10.3410/f. 737753881.793573903

Honarmand, K., Um, K. J., Belley-Cote, E. P., Alhazzani, W., Farley, C., Fernando, S. M., et al. (2020). Canadian Critical Care Society clinical practice guideline: the use of vasopressin and vasopressin analogues in critically ill adults with distributive shock. Can. J. Anaesth. 67, 369-376. doi:10.1007/s12630-01901546-x

Horby, P., Lim, W. S., and RECOVERY Collaborative Group. (2020). Dexamethasone in hospitalized patients with covid-19-preliminary report [published online ahead of print, 2020 Jul 17]. N. Engl. J. Med. 7, 19. doi:10. 1056/NEJMoa2021436

Huang, C., Wang, Y., Li, X., Ren, L., Zhao, J., Hu, Y., et al. (2020). Clinical features of patients infected with 2019 novel coronavirus in Wuhan, China. Lancet 395 (10223), 497-506. doi:10.1016/S0140-6736(20)30183-5

Interim Infection Prevention. (2020). Interim infection prevention and control recommendations for patients with suspected or confirmed coronavirus disease 2019 (COVID-19) in healthcare settings. Available from: https://www.cdc.gov/ coronavirus/2019-ncov/hcp/infection-control-recommendations.html?CDC_ AA_refVal=https\%3A\%2F\%2Fwww.cdc.gov\%2Fcoronavirus\%2F2019-ncov\% 2Finfection-control\%2Fcontrol-recommendations.html

Invernizzi, A., Pellegrini, M., Messenio, D., Cereda, M., Olivieri, P., Brambilla, A. M., et al. (2020a). Impending central retinal vein occlusion in a patient with coronavirus disease 2019 (COVID-19). Ocul. Immunol. Inflamm. 12 1-3.

Invernizzi, A., Torre, A., Parrulli, S., Zicarelli, F., Schiuma, M., Colombo, V., et al. (2020b). Retinal findings in patients with COVID-19: results from the SERPICO-19 study. E. Clin. Med. 27, 100550. doi:10.1016/j.eclinm.2020.100550

Jin, X., Lian, J. S., Hu, J. H., Gao, J., Zheng, L., Zhang, Y-M., et al. (2020b). Epidemiological, clinical and virological characteristics of 74 cases of coronavirus-infected disease 2019 (COVID-19) with gastrointestinal symptoms. Gut 69, 1002-1009. doi:10.1111/irv.12758/v1/review2

Jin, Y. H., Cai, L., and Cheng, Z. S. (2020a). A rapid advice guideline for the diagnosis and treatment of 2019 novel coronavirus (2019-nCoV) infected pneumonia (standard version). Mil. Med. Res. 7(1), 4. doi:10.1186/ s40779020-0233-6

Kampf, G., Todt, D., Pfaender, S., and Steinmann, E. (2020). Persistence of coronaviruses on inanimate surfaces and their inactivation with biocidal agents. J. Hosp. Infect. 104 (3), 246-251. doi:10.1016/j.jhin.2020.01.022

Karan, Abraar. (2020). To control the COVID-19 outbreak, young, healthy patients should avoid the emergency department. BMJ 368, m1040. doi:10.1136/bmj. m1040

Khosravani, H., Rajendram, H., Notario, L., Chapman, M. G., and Menon, B. K. (2020). Protected code stroke: Hyperacute stroke management during the coronavirus disease 2019 (COVID-19) pandemic stroke. Stroke 51, 838. doi:10.1161/STROKEAHA.120.029838 
Kisely, S., Warren, N., McMahon, L., Dalais, C., Henry, I., and Siskind, D. (2020). Occurrence, prevention, and management of the psychological effects of emerging virus outbreaks on healthcare workers: rapid review and metaanalysis. $B M J$ 369, m1642. doi:10.1136/bmj.m1642

Konstantinides, S. V., Meyer, G., Becattini, C., Bueno, H., Geersing, G. J., Harjola, V. P., et al. (2019). The Task Force for the management of acute pulmonary embolism of the European Society of C. 2019 ESC Guidelines for the diagnosis and management of acute pulmonary embolism developed in collaboration with the European Respiratory Society (ERS): the Task Force for the diagnosis and management of acute pulmonary embolism of the European Society of Cardiology (ESC). Eur. Respir. J. 54 (3), doi:10.3410/ f.736518177.793569467

Kooraki, S., Hosseiny, M., and Gholamrezanezhad, A. (2020). Radiologic findings of coronavirus disease (COVID-19): clinical correlation is recommended. AJR Am. J. Roentgenol. 1, 23. doi:10.2214/AJR.20.23211

Kotfis, K., Williams Roberson, S., Wilson, J. E., et al. (2020). COVID-19: ICU delirium management during SARS-CoV-2 pandemic. Crit. Care 24 (1), 176. doi:10.1186/s13054-020-02882-x

Koumpa, F. S., Forde, C. T., and Majaly, J. G. (2020). Sudden irreversible hearing loss post COVID-19. BMJ Case Rep. 12, 44. doi:10.1136/bcr-2020-238419 October 13, 2020

Krzeminski, P., Lesiak, A., and Narbutt, J. (2018). Seizures as a rare adverse effect of chloroquine therapy in systemic lupus erythematosus patients: a case report and literature survey. Postepy Dermatol. Alergol. 35 (4), 429-430. doi:10.5114/ada. 2018.77675

Lai, T. H. T., Tang, E. W. H., Chau, S. K. Y., Fung, K. S. C., and Li, K. K. W. (2020b). Stepping up infection control measures in ophthalmology during the novel coronavirus outbreak: an experience from Hong Kong. Graefes Arch. Clin. Exp. Ophthalmol. 19, 66. doi:10.1007/s00417-020-04641-8

Lai, T. H. T., Tang, E. W. H., Chau, S. K. Y., and Li, K. K. W. (2020a). Reply to ocular manifestation, eye protection, and COVID-19. Graefes Arch. Clin. Exp. Ophthalmol. 14, 55-59. doi:10.1007/s00417-020-04662-3

Lechien, J. R., Chiesa-Estomba, C. M., and De Siati, D. R. (2020). Olfactory and gustatory dysfunctions as a clinical presentation of mild-to-moderate forms of the coronavirus disease (COVID-19): a multicenter European study. Eur. Arch. Oto-Rhino-Laryngol. 4, 88-94. doi:10.1007/s00405-020-05965-1

Lewis, S. R., Pritchard, M. W., Evans, D. J., Butler, A. R., Alderson, P., Smith, A. F., et al. (2018). Colloids versus crystalloids for fluid resuscitation in critically ill people. Cochrane Database Syst. Rev. 8, CD000567. doi:10.3410/f.717995358. 793476448

Li, L., Zhang, W., Hu, Y., Tong, X., Zheng, S., Yang, J., et al. (2020a). Effect of convalescent plasma therapy on time to clinical improvement in patients with severe and life-threatening COVID-19: a randomized clinical trial. J. Am. Med. Assoc. 324 (5), 460-470. doi:10.1001/jama.2020.10044

Li, Y. C., Bai, W. Z., and Hashikawa, T. (2020b). The neuroinvasive potential of SARS-CoV2 may play a role in the respiratory failure of COVID-19 patients. J. Med. Virol. 33, 59. doi:10.1002/jmv.25728

Li, B., Yang, J., Zhao, F., Zhi, L., Wang, X., Liu, L., et al. (2020c). Prevalence and impact of cardiovascular metabolic diseases on COVID-19 in China. Clin. Res. Cardiol. 17, 55-108. doi:10.1007/s00392-020-01626-9

Li, J. O., Lam, D. S. C., Chen, Y., and Ting, D. S. W. (2020d). Novel Coronavirus disease 2019 (COVID-19): the importance of recognising possible early ocular manifestation and using protective eyewear. Br. J. Ophthalmol. 104 (3), 297-298. doi:10.1136/bjophthalmol-2020-315994

$\mathrm{Li}, \mathrm{X}$., and Ma, X. (2020). Acute respiratory failure in COVID-19: is it "typical" ARDS?. Crit. Care 24, 198. doi:10.1186/s13054-020-02911-9

Li, Y. C., Bai, W. Z., Hirano, N., Hayashida, T., and Hashikawa, T. (2012). Coronavirus infection of rat dorsal root ganglia: ultrastructural characterization of viral replication, transfer, and the early response of satellite cells. Virus Res. 16, 628-635. doi:10.1016/j.virusres.2011.12.021

Liang, E. W., Fua, T.-P., and Chua, Y. Y. (2020). Containing COVID-19 in the emergency room: the role of improved case detection and segregation of suspect cases. Acad. Emerg. Med. 22, 91-98. doi:10.1111/acem.13984

Liu, P. P., Blet, A., Smyth, D., and Li, H. (2020a). The science underlying COVID19: implications for the cardiovascular system. Circulation. 28, 14. doi:10.1161/ CIRCULATIONAHA. 120.047549

Liu, Y., Yang, Y., Zhang, C., Huang, F., Wang, F., Yuan, J., et al. (2020b). Clinical and biochemical indexes from $2019-\mathrm{nCoV}$ infected patients linked to viral loads and lung injury. Sci. China Life Sci. 63 (3), 364-374. doi:10.1360/ssv2020-0037

Lopes, N., Vernuccio, F., and Costantino, C. (2020). An Italian guidance model for the management of suspected or confirmed covid-19 patients in the primary care setting. Front. Pub. Health 44, 198. doi:10.3389/fpubh.2020.572042

Lu, C. W., Liu, X. F., and Jia, Z. F. (2020a). 2019-nCoV transmission through the ocular surface must not be ignored. Lancet 395 (10224), e39. doi:10.1016/s01406736(20)30313-5

Lu, K.-L., Chen, S., and Leung, L.-P. (2020b). Initial experience of an emergency department in shenzhen in responding to the emerging Wuhan coronavirus pneumonia. Ann. Emerg. Med. 75 (4), 556. doi:10.1016/j.annemergmed.2020.02.006

Madjid, M., Safavi-Naeini, P., Solomon, S. D., and Vardeny, O. (2020). Potential effects of coronaviruses on the cardiovascular system: a review. JAMA Cardiol 5, 6. doi:10.1001/jamacardio.2020.1286

Mao, L., Wang, M., Chen, S., He, Q., Chang, J., Hong, C., et al. (2020). Neurological manifestations of hospitalized patients with COVID-19 in Wuhan, China. JAMA Neurol. 9, 16. doi:10.1001/jamaneurol.2020.1127

Marinho, P. M., Marcos, A. A. A., Romano, A. C., Nascimento, H., and Belfort, R., Jr. (2020). Retinal findings in patients with COVID-19. Lancet 395 (10237), 1610. doi:10.1016/s0140-6736(20)31912-7

Marini, J. J., and Gattinoni, L. (2020). Management of COVID-19 respiratory distress. J. Am. Med. Assoc. 323 (22), 2329-2330. doi:10.1001/jama.2020.6825

Meyhoff, T. S., Moller, M. H., Hjortrup, P. B., Cronhjort, M., Perner, A., and Wetterslev, J. (2020) Lower versus higher fluid volumes during initial management of sepsis: a systematic review with meta-analysis and trial sequential analysis. Chest 67, 181-188. doi:10.1016/j.chest.2019.11.050

Ministero della salute (2020). Ministero della salute, Consiglio Superiore di Sanità 165. Available from: http://www.trovanorme.salute.gov.it/norme/ renderNormsanPdf?anno $=2020 \&$ codLeg $=73458 \&$ parte $=1 \% 20 \&$ serie $=$ null.

Leiva-Juárez, M. M., Kolls, J. K., and Evans, S. E. (2018). Lung epithelial cells: therapeutically inducible effectors of antimicrobial defense, Mucosal. Immunol 11, 21-34. doi:10.1038/mi.2017.71

Mojoli, F., Bouhemad, B., Mongodi, S., and Lichtenstein, D. (2019). Lung ultrasound for critically ill patients [published correction appears in Am J respir crit care med. 2020 apr 15;201(8):1015]. Am. J. Respir. Crit. Care Med. 199 (6), 701-714. doi:10.1164/rccm.201802-0236CI

Moller, M. H., Claudius, C., Junttila, E., Haney, M., Oscarsson-Tibblin, A., Haavind, A., et al. (2016). Scandinavian SSAI clinical practice guideline on choice of first-line vasopressor for patients with acute circulatory failure. Acta Anaesthesiol. Scand. 60, 1347-1366. doi:10.1111/aas.12780

Moller, M. H., Granholm, A., Junttila, E., Haney, M., Oscarsson-Tibblin, A., Haavind, A., et al. (2018). Scandinavian SSAI clinical practice guideline on choice of inotropic agent for patients with acute circulatory failure. Acta Anaesthesiol. Scand. 62, 420-450. doi:10.1111/aas.13089

Mungmungpuntipantip, R., and Wiwanitkit, V. (2020). Ocular manifestation, eye protection, and COVID-19. Graefes Arch. Clin. Exp. Ophthalmol. 258, 1339. doi:10.1007/s00417-020-04662-3

Netland, J., Meyerholz, D. K., Moore, S., Cassell, M., and Perlman, S.(2008). Severe acute respiratory syndrome coronavirus infection causes neuronal death in the absence of encephalitis in mice transgenic for human ACE2. J. Virol. 82 (15), 7264-7275. doi:10.1128/jvi.00737-08

NHS Specialty Guides. (2020). NHS Specialty guides for patient management during the coronavirus pandemic. Available from: https://www.england.nhs.uk/ coronavirus/publication/specialtyguides/.

Oldenburg, C. E., and Doan, T. (2020). Azithromycin for severe COVID-19. Lancet 396 (10256), 936-937. doi:10.1016/S0140-6736(20)31863-8

Paganini, M., Conti, A., Weinstein, E., Della Corte, F., and Ragazzoni, L. (2020). Translating COVID-19 pandemic surge theory to practice in the emergency department: how to expand structure. Disaster Med. Public Health Prep. 12, 1-10. doi:10.1017/dmp.2020.57

Paglia, S., Storti, E., and Magnacavallo, A. (2020) Rapporto Prima Linea COVID-19 assetto organizzativo gestionale dei PS/DEA nell'ambito di focolaio epidemico o preepidemico. Vienna, Austria: SIMEU Società Italiana Medicina d'EmergenzaUrgenza.

Pamplona, J., Solano, R., Soler, C., and Sabat, M. (2020). Epidemiological approximation of the enteric manifestation and possible fecal-oral transmission in COVID-19: a preliminary systematic review. Eur. J. Gastroenterol. Hepatol. 7, 18-25. doi:10.1097/MEG.0000000000001934 
Pan, J., Peng, M., Liao, C., Hu, X., Wang, A., and Li, X. (2019). Relative efficacy and safety of early lactate clearance-guided therapy resuscitation in patients with sepsis: a meta-analysis. Medicine 98, e14453. doi:10.1097/md. 0000000000014453

Pan, Y., Zhang, D., and Yang, P. (2020). Viral load of SARS-CoV-2 in clinical samples. Lancet Infect. Dis. 20, 411-412.

Peng, Q. Y., Wang, X. T., and Zhang, L. N. (2020). Chinese Critical Care Ultrasound Study Group (CCUSG). Findings of lung ultrasonography of novel corona virus pneumonia during the 2019-2020 epidemic [published online ahead of print, 2020 Mar 12]. Intens. Care Med. 1-2, 19. doi:10.1007/ s00134-020-05996-6

Pfefferbaum, B., and North, C. S. (2020). Mental health and the covid-19 pandemic. N. Engl. J. Med. 383 (6), 510. doi:10.1016/j.jcv.2020.104439

Poissy, J., Goutay, J., and Caplan, M. (2020). Pulmonary embolism in COVID-19 patients: awareness of an increased prevalence. Amsterdam: Elsevier. doi:10. 1161/CIRCULATIONAHA.120.047430

Poyiadji, N., Shahin, G., and Noujaim, D. (2020). COVID-19-associated acute hemorrhagic necrotizing encephalopathy: CT and MRI features. Radiology 19, 201187. doi:10.1148/radiol.2020201187

Pritchett, M. A., Oberg, C. L., Belanger, A., De Cardenas, J., Cheng, G., Nacheli, G. C., et al. (2020). Society for advanced bronchoscopy consensus statement and guidelines for bronchoscopy and airway management amid the COVID-19 pandemic. J. Thorac. Dis. 12 (5), 1781-1798. doi:10.21037/jtd.2020.04.32

Procedura Regionale Nuovo Coronavirus Sars. (2020). Procedura Regionale Nuovo Coronavirus Sars cov-19 regione veneto rev 02.03.2020. Available from: https:// www.regione.veneto.it/web/sanita/covid-19documenti-regionali-operatore

Qing, H., Li, Z., Yang, Z., Shi, M., Huang, Z., Song, J., et al. (2020). The possibility of COVID-19 transmission from eye to nose. Acta Ophthalmol. 98, 24. doi:10. $1111 /$ aos. 14412

Ranieri, V. M., ARDS Definition Task Force. (2012). Acute respiratory distress syndrome: the Berlin Definition. J. Am. Med. Assoc. 307 (23), 2526-2533. doi:10.1001/jama.2012.5669

Rauch, B. (2020). Cost-effectiveness of rivaroxaban plus aspirin (dual pathway inhibition) for prevention of ischaemic events in patients with cardiovascular disease: on top optimisation of secondary prevention medication in the context of COVID-19 pandemia [published online ahead of print, 2020 Apr 17]. Eur. J. Prev. Cardiol. 15, 2047487320920754. doi:10.1177/2047487320920754

RCEM Quality Policy. (2020). Available from: https://www.rcem.ac.uk/RCEM/ Quality_Policy/Clinical_Standards_Guidance/Local_Guidance/RCEM/QualityPolicy/ Clinical_Standards_Guidance/Local_Guidance.aspx?hkey=123765ca3b-617c-427ca4af-57fca689a0de (Accessed April 29, 2020).

Rhodes, A., Evans, L. E., and Alhazzani, W. (2016). Surviving Sepsis Campaign: international guidelines for management of sepsis and septic shock. Crit. Care Med. 45 (3), 486-552. doi:10.1097/ccm.0000000000000192

Turer, R. W., Jones, I., Rosenbloom, S. T., Corey, S., and Ward, M. J. (2020). Electronic personal protective equipment: a strategy to protect emergency department providers in the age of COVID-19, J. Am. Med. Inf. Assoc. 14, ocaa048. doi:10.1093/jamia/ocaa048

Rodrigues Prestes, T. R., Rocha, N. P., Miranda, A. S., Teixeira, A. L., and Simoes, E. S. A. C. (2017). The anti-inflammatory potential of ACE2/angiotensin-(1-7)/ mas receptor Axis: evidence from basic and clinical research. Curr. Drug Targets 18 (11), 13011313. doi:10.2174/1389450117666160727142401

Rodriguez-Morales, A. J., Cardona-Ospina, J. A., and Gutiérrez-Ocampo, E. (2020). Clinical, laboratory and imaging features of COVID-19: a systematic review and metaanalysis. Trav. Med. Infect. Dis. 34, 101623. doi:10.1016/j. tmaid.2020.101623

Rogers, J. P., Chesney, E., Oliver, D., Pollak, T. A., McGuire, P., Fusar-Poli, P., et al. (2020). Psychiatric and neuropsychiatric presentations associated with severe coronavirus infections: a systematic review and meta-analysis with comparison to the COVID-19 pandemic. Lancet Psych. 7 (7), 611. doi:10.1016/s22150366(20)30203-0

Romano, M. R., Montericcio, A., Montalbano, C., Raimondi, R., Allegrini, D., Ricciardelli, G., et al. (2020). Facing COVID-19 in ophthalmology department. Curr. Eye Res. 12, 27. doi:10.1080/02713683.2020.1764053

Rossi, R., Socci, V., Pacitti, F., Di Lorenzo, G., Di Marco, A., Siracusano, A., et al. (2020). Mental health outcomes among Frontline and second-line health care workers during the coronavirus disease 2019 (COVID-19) pandemic in Italy. JAMA Netw Open 3 (5), e2010185. doi:10.1001/jamanetworkopen.2020.10185
Ruan, Q., Yang, K., Wang, W., Jiang, L., and Song, J. (2020). Clinical predictors of mortality due to COVID-19 based on an analysis of data of 150 patients from Wuhan, China. Intens. Care Med. 19, 20. doi:10.1007/s0013 4-020-05991-x

Rubin, G. D., Ryerson, C. J., Haramati, L. B., Sverzellati, N., Kanne, J. P., Raoof, S., et al. (2020). The role of chest imaging in patient management during the COVID-19 pandemic: a multinational consensus statement from the Fleischner society, Chest 7, 19-33. doi:10.1016/j.chest.2020.04.003

Salehi, S., Abedi, A., and Balakrishnan, S. (2019). COVID-19: a systematic review of imaging findings in 919 patients. AJR Am. J. Roentgenol. 12, 1-7. doi:10.2214/ AJR.20.23034

Sanders, J. M. (2020). Pharmacologic treatments for coronavirus disease 2019 (COVID-19): a review. J. Am. Med. Assoc. 19, 45-74. doi:10.1001/jama.2020.6019

Saravia, S. A., Raynor, P. C., and Streifel, A. J. (2007). A performance assessment of airborne infection isolation rooms. Am. J. Infect. Contr. 35 (5), 324-331. doi:10. 1016/j.ajic.2006.10.012

Schuetz, P., Wirz, Y., Sager, R., Christ-Crain, M., Stolz, D., Tamm, M., et al. (2017). Procalcitonin to initiate or discontinue antibiotics in acute respiratory tract infections. Cochrane Database Syst. Rev. 10, 7498. doi:10.1002/14651858. CD007498.pub3

Senanayake, Pd., Drazba, J., Shadrach, K., Milsted, A., Rungger-Brandle, E., Nishiyama, K., et al. (2007). Angiotensin II and its receptor subtypes in the human retina. Invest. Ophthalmol. Vis. Sci. 48 (7), 3301-3311. doi:10.1007/9781-4615-2464-9_8

Shen, C. (2020). Treatment of 5 critically ill patients with COVID-19 with convalescent plasma. J. Am. Med. Assoc. 158, A601. doi:10.1016/j.chest.2020.08.566

Shi, Y., Wang, Y., Shao, C., Huang, J., Gan, J., Huang, X., et al. (2020). COVID-19 infection: the perspectives on immune responses Cell Death \& Differentiation march 2020. Berlin: Springer.

Singer, M., Deutschman, C. S., and Seymour, C. W. (2016). The third international consensus definitions for sepsis and septic shock (Sepsis-3). J. Am. Med. Assoc. 315 (8), 801-810. doi:10.1001/jama.2016.0287

Skipper, C. P., Pastick, K. A., Engen, N. W., Bangdiwala, A. S., Abassi, M., Lofgren, S. M., et al. (2020). Hydroxychloroquine in nonhospitalized adults with early COVID-19 : a randomized trial. Ann. Intern. Med. 11, M20-M4207. doi:10. 7326/M20-4207

Soldati, G., Smargiassi, A., Inchingolo, R., Buonsenso, D., Perrone, T., Briganti, D. F., et al. (2020b). Proposal for international standardization of the use of lung ultrasound for patients with COVID-19. J. Ultrasound Med. 8, 14. doi:10.1002/ jum. 15285

Soldati, G., Smargiassi, A., Inchingolo, R., Buonsenso, D., Perrone, T., and Briganti, D. F. (2020a). Is there a role for lung ultrasound during the COVID-19 pandemic?. J. Ultrasound Med. 3, 28. doi:10.1002/jum.15284

Solomon, M. D., McNulty, E. J., Rana, J. S., Leong, T. K., Lee, C., Sung, S. H., et al. (2020). The covid-19 pandemic and the incidence of acute myocardial infarction. N. Engl. J. Med. 383 (7), 691. doi:10.1056/NEJMc2015630

Sommer, A. (2020). Humans, viruses, and the eye-an early report from the COVID-19 Front line. JAMA Ophthalmol. 138, 578. doi:10.1001/ jamaophthalmol.2020.1294

Steardo, L., Jr, Steardo, L., and Verkhratsky, Alexei. (2020). Psychiatric face of COVID-19. Transl. Psychiatry 10 (1), 261. doi:10.1038/s41398-020-00949-5

Tan, C., Huang, Y., and Shi, F. (2020). C-reactive protein correlates with computed tomographic findings and predicts severe COVID-19 early. J. Med. Virol. 19, 1-7. doi:10.1002/jmv.25871

Tao, A., Yang, Z., Hou, H., Zhan, C., Chen, C., Lv, W., et al. (2020). Correlation of chest CT and RT-PCR testing in coronavirus disease 2019 (COVID-19) in China: a report of 1014 cases. Radiology 9, 200642. doi:10.1148/radiol. 2020200642

The ARDS Definition Task Force. (2012). Acute respiratory distress syndrome: the Berlin definition. J. Am. Med. Assoc. 307 (23), 2526-2533. doi:10.1001/jama. 2012.5669

Thygesen, K., Alpert, J. S., Jaffe, A. S., Chaitman, B. R., JeroenBax, J. D., et al. (2018). Executive group on behalf of the Joint European society of cardiology (ESC)/ American college of cardiology (ACC)/American heart association (AHA)/World heart Federation (WHF) task Force for the universal definition of myocardial infarction. Fourth universal definition of myocardial infarction (2018). J. Am. Coll. Cardiol. 72 (18), 2231-2264. doi:10.1016/j.jacc.2018.08.1038

Tinku, J. (2020). International Pulmonologist's consensus on COVID19. 2nd Edn. Berlin, Germany: Springer. 
Toscano, G., Palmerini, F., Ravaglia, S., et al. (2020). Guillain-barré syndrome associated with SARS-CoV-2. N. Engl. J. Med. 64, 117-233. doi:10.1056/ NEJMc2009191

Turtle, L. (2020). Respiratory failure alone does not suggest central nervous system invasion by SARS-CoV-2. J. Med. Virol. 19, 18-27. doi:10.1002/jmv.25828

Vavvas, D. G., Sarraf, D., Sadda, S. R., Eliott, D., Ehlers, J. P., Waheed, N. K., et al. (2020). Concerns about the interpretation of OCT and fundus findings in COVID-19 patients in recent Lancet publication. Eye 7, 1-2. doi:10.1038/ s41433-020-1084-9

Vernuccio, F., Giambelluca, D., Cannella, R., Lombardo, F. P., Panzuto, F., Midiri, M., et al. (2020). Radiographic and chest CT imaging presentation and followup of COVID-19 pneumonia: a multicenter experience from an endemic area. Emerg. Radiol. 8, 1-10. doi:10.1007/s10140-020-01817-x

Vinores, S. A., Wang, Y., Vinores, M. A., Derevjanik, N. L., Shi, A., Klein, D. A., et al. (2001). Blood-retinal barrier breakdown in experimental coronavirus retinopathy: association with viral antigen, inflammation, and VEGF in sensitive and resistant strains. J. Neuroimmunol. 119 (2), 175-182. doi:10. 1016/s0165-5728(01)00374-5

Wagner, J., Jan Danser, A. H., Derkx, F. H., de Jong, T. V., Paul, M., Mullins, J. J., et al. (1996). Demonstration of renin mRNA, angiotensinogen mRNA, and angiotensin converting enzyme mRNA expression in the human eye: evidence for an intraocular renin-angiotensin system. Br. J. Ophthalmol. 80 (2), 159-163.

Walkey, A. J., Hammill, B. G., Curtis, L. H., and Benjamin, E. J. (2014). Long-term outcomes following development of new-onset atrial fibrillation during sepsis. Chest 146 (5), 11871195. doi:10.1378/chest.14-0003

Walls, A. C., Park, Y. J., Tortorici, M. A., Wall, A., McGuire, A. T., and Veesler, D. (2020). Structure, function, and antigenicity of the SARS-CoV-2 spike glycoprotein. Berlin, Germany: Springer. doi:10.1016/j.cell.2020.02.058

Wan, K. H., Huang, S. S., Young, A., and Chiu Lam, D. S. (2020a). Precautionary measures needed for ophthalmologists during pandemic of the coronavirus disease 2019 (COVID-19). Acta Ophthalmol. 98, 221-228. doi:10.1111/aos. 14438

Wan, Y., Shang, J., Graham, R., Baric, R. S., and Li, F. (2020b). Receptor recognition by novel coronavirus from Wuhan: an analysis based on decade-long structural studies of SARS. J. Virol. 94, e00127-20

Wang, C., Pan, R., Wan, X., Tan, Y., Xu, L., Ho, C. S., et al. (2020c). Immediate psychological responses and associated factors during the initial stage of the 2019 coronavirus disease (COVID-19) epidemic among the general population in China. Int. J. Environ. Res. Publ. Health 17, 1729. doi:10.3390/ijerph17051729

Wang, D., Hu, B., Hu, C., Zhu, F., Liu, X., Zhang, J., et al. (2020a). Clinical characteristics of 138 hospitalized patients with 2019 novel coronavirusinfected pneumonia in Wuhan, China. J. Am. Med. Assoc. 323 (11), 1061. doi:10.1001/jama.2020.1585

Wang, W., Xu, Y., and Gao, R. (2020b). Detection of SARS-CoV-2 in different types of clinical specimens. JAMA 11 27. doi:10.1001/jama.2020.3786

Wax, R. S., et al. (2020). Practical recommendations for critical care and anesthesiology teams caring for novel coronavirus (2019-nCoV) patients. Can. J. Anaesth. 33, 55. doi:10.1007/s12630-020-01591-x

Wittbold, K. A., Baugh, J. J., Brian, J., and Yun, H. (2020). iPad deployment for virtual evaluation in the emergency department during the COVID-19 pandemic. Am. J. Emerg. Med. 7, 98. doi:10.1016/j.ajem.2020.04.025 12

World Health Organization. (2020a). Clinical management of severe acute respiratory infection when novel coronavirus $(2019-n \mathrm{CoV})$ infection is suspectedInterim guidance. Geneva, Switzerland: WHO.
World Health Organization. (2020b). Global surveillance for COVID-19 disease caused by human infection with the 2019 novel coronavirus. Geneva, Switzerland: WHO.

World Health Organization. (2020c). Report of the WHO-China joint mission on coronavirus disease 2019 (COVID-19). Geneva, Switzerland: WHO.

Wu, P., Duan, F., Luo, C., Liu, Q., Qu, X., Liang, L., et al. (2020a). Characteristics of ocular findings of patients with coronavirus disease 2019 (COVID-19) in Hubei province, China. JAMA Ophthalmol. 12, 17. doi:10.37473/fic/10.1101/2020.04. 02.20050989

Wu, Y., Guo, C., Tang, L., Hong, Z., Zhou, J., Dong, X., et al. (2020b). Prolonged presence of SARS-CoV-2 viral RNA in faecal samples. Lancet Gastroenterol. Hepatol. 5, 434-435. doi:10.37473/dac/10.1101/2020.04.26.20081307

Wu, Z., and McGoogan, J. M. (2020). Characteristics of and important lessons from the coronavirus disease 2019 (COVID-19) outbreak in China: summary of a report of 72314 cases from the Chinese center for disease control and prevention. J. Am. Med. Assoc. 323 (13), 1239-1242. doi:10.1001/jama.2020.2648

Xia, J., Tong, J., Liu, M., Shen, Y., and Guo, D. (2020). Evaluation of coronavirus in tears and conjunctival secretions of patients with SARS-CoV-2 infection. J. Med. Virol. 92, 589-594. doi:10.1002/jmv.25725

Xu, L., Liu, J., Lu, M., Yang, D., and Zheng, X. (2020a). Liver injury during highly pathogenic human coronavirus infections. Liver Int. 40, 998-1004. doi:10.1111/ liv. 14435

Xu, Z., Shi, L., Wang, Y., Zhang, J., Huang, L., Zhang, C., et al. (2020b). Pathological findings of COVID-19 associated with acute respiratory distress syndrome. Lancet Respirat. Med. 121, 47. doi:10.1016/S2213-2600(20)30076-X

Yang, X., Yu, Y., Xu, J., Shu, H., Xia, J., Liu, H., et al. (2020). Clinical course and outcomes of critically ill patients with SARS-CoV-2 pneumonia in Wuhan, China: a single-centered, retrospective, observational study. Lancet Respir. Med. 2, 66. doi:10.1016/S2213-2600(20)30079-5

Zhang, Y., Xiao, M., and Zhang, S. (2020a). Coagulopathy and antiphospholipid antibodies in patients with covid-19. N. Engl. J. Med. 11, e38. doi:10.1056/ NEJMc2007575

Zhang, C., Wu, Z., Li, J.-W., Zhao, H., and Wang, G.-Q. (2020b). Cytokine release syndrome in severe COVID-19: interleukin-6 receptor antagonist tocilizumab may be the key to reduce mortality. Int. J. Antimicrob. Agents 55, 105954. doi:10. 1016/j.ijantimicag.2020.105954

Zhao, H., Shen, D., Zhou, H., Liu, J., and Chen, S. (2020a). Guillain-Barré syndrome associated with SARS-CoV-2 infection: causality or coincidence?. Lancet Neurol. 20, 383-384. doi:10.1016/S1474-4422(20)30109-5

Zhao, Y., Zhao, Z., Wang, Y., Zhou, Y., Ma, Y., and Zuo, W. (2020b). Single-cell RNA expression profiling of ACE2, the putative receptor ofWuhan 2019-nCov. bioRxiv 21, 32. doi:10.1101/2020.01.26.919985

Conflict of Interest: The authors declare that the research was conducted in the absence of any commercial or financial relationships that could be construed as a potential conflict of interest.

Copyright (c) 2020 Lo Bianco, Di Pietro, Mazzuca, Imburgia, Tarantino, Accurso, Benenati, Vernuccio, Bucolo, Salomone and Riolo. This is an open-access article distributed under the terms of the Creative Commons Attribution License (CC BY). The use, distribution or reproduction in other forums is permitted, provided the original author(s) and the copyright owner(s) are credited and that the original publication in this journal is cited, in accordance with accepted academic practice. No use, distribution or reproduction is permitted which does not comply with these terms. 